\title{
China's corridor bridges: heritage buildings over water
}

\author{
Ronald G. Knapp ${ }^{1 *}$ (D) Terry E. Miller ${ }^{2}$ and Jie Liu ${ }^{3}$
}

\begin{abstract}
Essentially unknown in the rest of the world and only recently appreciated in China, the globally significant 3000+ 'corridor bridges' (Iangaiao) in China far outnumber the better-known 'covered bridges' found in North America and Europe. Rivaling or exceeding those in the West in number, age, complexity, and architectural ambition, some of China's outstanding timber langqiao in the mountains of Fujian and Zhejiang provinces are on the cusp of being inscribed as UNESCO World Heritage cultural sites. Throughout south and central China today there is moreover a resurgence of new timber langqiao being erected using traditional carpentry alongside the unprecedented construction of modern marvels of steel and concrete.

Archaeological evidence in 2001 uncovered China's earliest 'corridor bridge' - thus the oldest known covered bridge in the world - with a length of $42 \mathrm{~m}$ dating to the Han dynasty 2000 years ago. The Rulong Bridge, which dates to 1625 and is documented as the oldest standing woven arch-beam langqiao, can be visited today in Qingyuan county, southern Zhejiang. Even older langqiao with parallel log beams as the substructure have come to light in neighboring Fujian province, most notably the Zhiqing Bridge in a rural area of Jian'ou city that dates to 1490.

China's bridges, whether with a corridor atop or without, have traditionally not been included under the umbrella of 'vernacular architecture' even as they usually were created by local craftspeople employing the same approaches and practices for dwellings and temples. Just as with these better researched structures, langqiao must be studied not only from the perspective of architecture, but also anthropology, geography, history, and sociology, among other disciplines. Rather than being abandoned as artifacts from the past, China's langqiao today represent a living tradition that continues serving rural communities as places of passage, spaces for leisure and marketing, sites for worship, and increasingly destinations for tourists in search of nostalgic connections with China's past.

The research presented in this article draws heavily from the authors' China's Covered Bridges: Architecture over Water, a comprehensive book published in late 2019 in Shanghai and London by Shanghai Jiao Tong University Press that will be distributed in 2020 by the University of Hawai'i Press. Despite the scope of this book, the complexity of China's langqiao remains understudied.
\end{abstract}

Keywords: Corridor bridges, Covered bridges, Heritage tourism, Langqiao, Rural tourism, Vernacular architecture

\section{Introduction}

Discovery of the significance of the architectural typology known in China as 'corridor bridge' has emerged slowly. Knapp's research in the countryside, which began in 1965 in Taiwan and then expanded to the China mainland from

\footnotetext{
* Correspondence: knappr@newpaltz.edu

'SUNY Distinguished Professor Emeritus, State University of New York, PO Box 365 New Paltz, New York 12561, USA

Full list of author information is available at the end of the article
}

1977 onward, focused on documenting old rural dwellings and broader aspects of vernacular architecture in villages. ${ }^{1}$ Early on, as was the common practice of academics writing about China's rural landscapes then, bridges, like old houses, pagodas, ancestral halls, gravesites, and temples were generally viewed as merely surviving remnants from the past of once complete villages.

\footnotetext{
${ }^{1}$ An exploration of this can be viewed at https://www.built-heritage. net/ronald-knapp-interview
}

\section{Springer Open}

(c) The Author(s). 2020 Open Access This article is licensed under a Creative Commons Attribution 4.0 International License, which permits use, sharing, adaptation, distribution and reproduction in any medium or format, as long as you give appropriate credit to the original author(s) and the source, provide a link to the Creative Commons licence, and indicate if changes were made. The images or other third party material in this article are included in the article's Creative Commons licence, unless indicated otherwise in a credit line to the material. If material is not included in the article's Creative Commons licence and your intended use is not permitted by statutory regulation or exceeds the permitted use, you will need to obtain permission directly from the copyright holder. To view a copy of this licence, visit http://creativecommons.org/licenses/by/4.0/. 


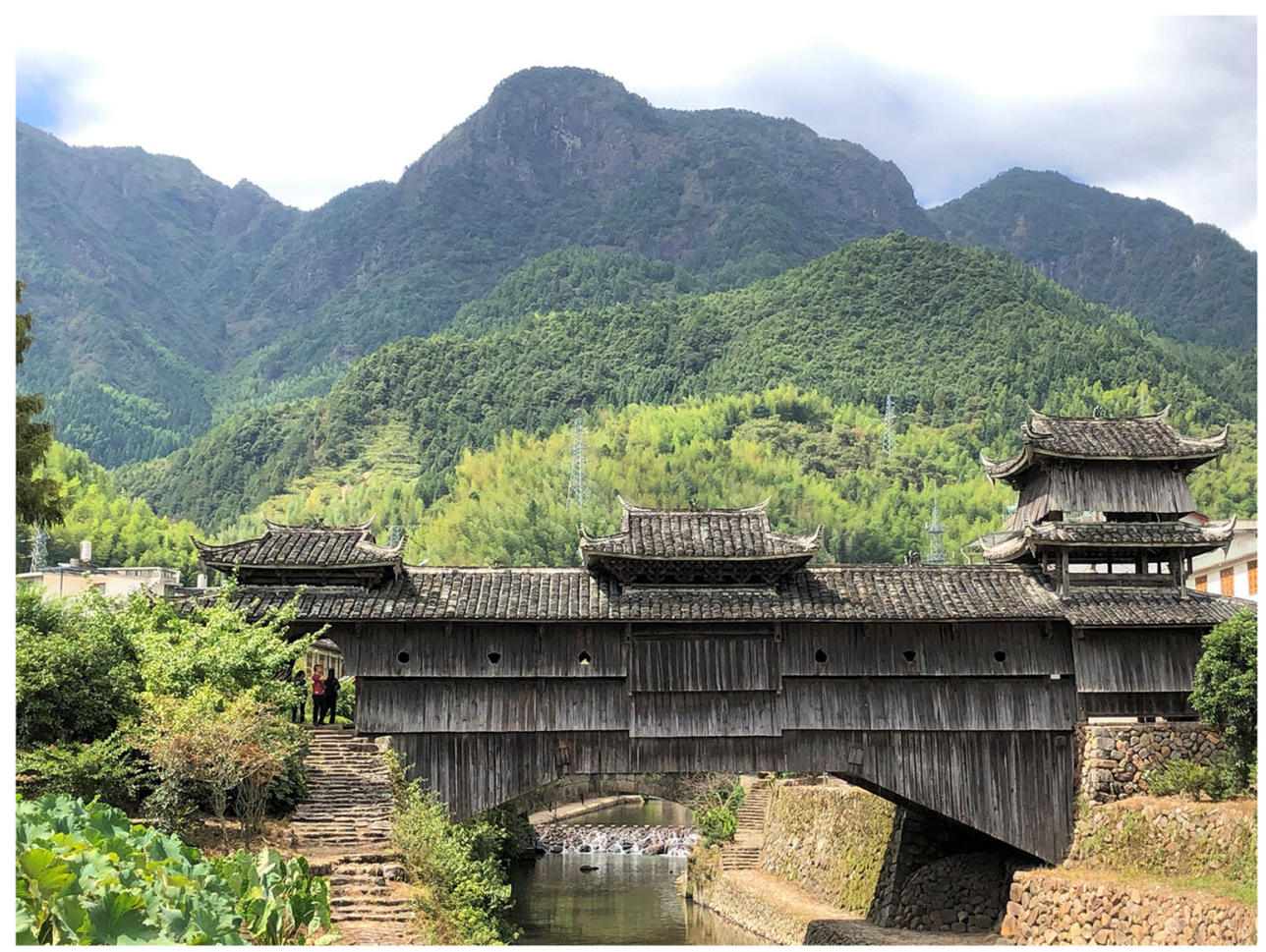

Fig. 1 Based on extensive documentary evidence, the Rulong Bridge, Qingyuan county, Zhejiang, which dates to 1625, is China's oldest woven arch-beam langqiao (Source: Ronald G. Knapp, 2019)

In time, however, it became clear that bridges-especially those with a timber roof and siding-were more than traditional buildings that embodied the work of carpenters and masons, but also could be seen as significant components of China's broader traditional economic and social life. Driven by a succession of conferences organised by Liu Jie of Shanghai Jiao Tong University in the first decade of the 21st century, a score of academics and amateurs began to build an interest in the subject. The inaugural conference in 2005, which Knapp attended, was held

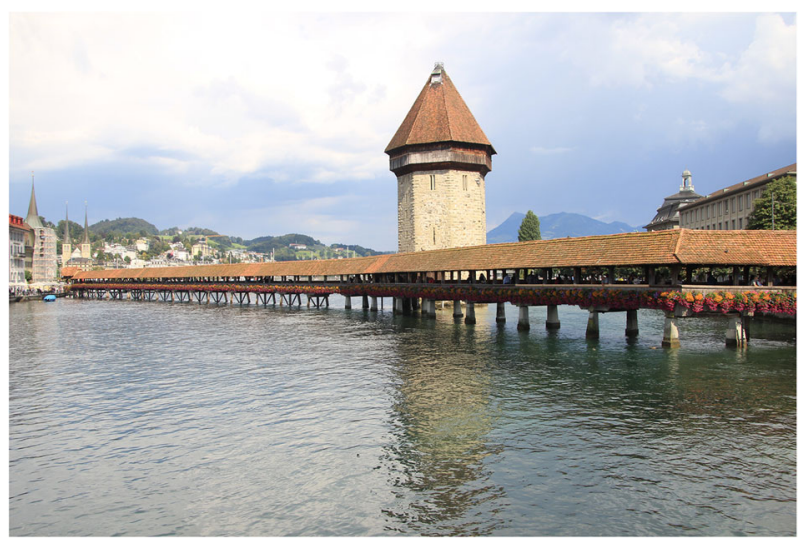

Fig. 2 Frequently touted as the oldest covered bridge in Europe, the Kapellbrücke in Lucerne, Switzerland has been rebuilt many times (Source: Terry E. Miller, 2016) in Zhejiang's Taishun County at that time considered the major site for timber bridges. However, as successive conferences were held-Shouning, Fujian in 2007; Pingnan, Fujian in 2009; Qingyuan, Zhejiang in 2011; and jointly in Zhenghe, Fujian and Taishun, Zhejiang in 2013-it became quite clear that there was a broader area of shared building history than that of a single mountainous county (Fig. 1). In 2017, the conference moved beyond Fujian and Zhejiang to Zhuoshui, Qianjiang District, Chongqing $\mathrm{Mu}$ nicipality. In 2019, the conference returned to Qingyuan, Zhejiang. Each of these conferences as well as intervening field work provided opportunities for the authors to discover new bridges worth assessing across seven areas of China (Map). Throughout this decade and a half, Liu Jie continued to publish important books that have provided new perspectives on langqiao (Liu and Shen 2005, Liu 2009, Liu 2017; Liu and CHTS (China Highway and Transportation Society) 2019).

Amidst these conferences, in 2009 the 'Traditional Design and Practices for Building Chinese Wooden Arch Bridges' was inscribed on the UNESCO List of Intangible Cultural Heritage in Need of Urgent Safeguarding via an application that had local, provincial, and national support. This effort recognised that only a handful of aging craftspeople were in a position to transmit their knowledge and skills. Very quickly efforts were put in place to support these individuals and recruit apprentices to be 


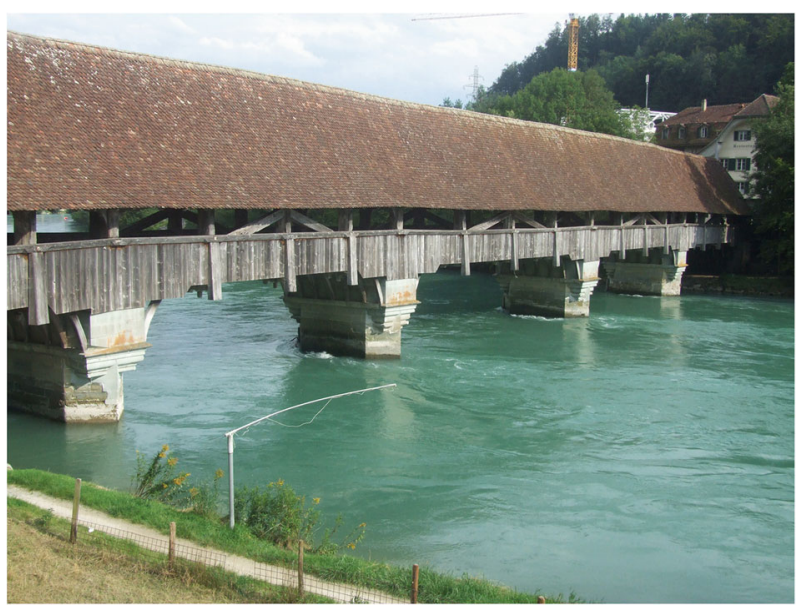

Fig. 3 Constructed in 1535 of massive-sized timbers, Switzerland's Neubrügg (Neubrücke) spanning the river Aare consists of short kingpost trusses. It continues to carry vehicle traffic today (Source: Terry E. Miller 2014)

trained. Moreover, seven counties straddling the border between Fujian and Zhejiang began in late 2012 to work together in an unprecedented joint application seeking UNESCO World Heritage status for 'Fujian-Zhejiang Wooden Arch-Beam Bridges'. ${ }^{2}$

Knapp published Chinese Bridges: Living Architecture from China's Past (Knapp 2008a) and an article 'Rainbows and Centipedes: Twentieth Century Discoveries of China's "Lost Bridges"' (Knapp 2008b), which presented for the first time in English the magnificent wooden arch-beam bridges in Fujian and Zhejiang, complementing well Klaus Zwerger's Vanishing Tradition: Architecture and Carpentry of the Dong Minority (Zwerger 2006). Meanwhile, Knapp embarked with Terry Miller, an acknowledged expert on North America's covered bridges, on a multi-year research project that led to the publication America's Covered Bridges: Practical Crossings-Nostalgic Icons (Terry E. Miller 2014), which has been heralded as the definitive book on the subject.

These field experiences and approaches provided templates for China's Covered Bridges: Architecture over Water (Knapp et al. 2019), which not only document with text, drawings, and high-quality photography the range of this architectural typology, but also compares and contrasts those in China with better known covered bridges in North America and Europe. Langqiao wenhua, 'corridor bridge culture', is today being promoted by tourist organisations via electronic and print media as having tremendous cultural heritage value. Indeed, already some counties not only have become tourist meccas for their

\footnotetext{
${ }^{2}$ For additional information, visit the official website for this joint effort http://sy.langqiao.net/index.php
}

bridges, as is the case in North America and Europe, but also as sites for destination weddings where langqiao are at the centre of a couple's photographic record. Enthusiastic boosterism unfortunately has led to hyperbolic and confusing assertions that seek to identify 'the oldest', 'the longest', 'the highest', and 'the most beautiful' langqiao, often confusing the casual tourist about the authenticity and integrity of what they encounter.

\section{Bridges as buildings}

Bridges usually are not thought of as 'buildings' even as they clearly are 'structures'. Unlike dwellings, churches, temples, mills, and palaces that may be constructed of similar materials, bridges traditionally have been less visible and rarely appreciated even as structures, let alone as buildings. Indeed, all too often bridges throughout the world have been considered mere utilitarian elements of a cultural landscape, a necessary linkage along a route for the passage of people, animals, and conveyances of many types. Craftspeople through history utilised stone, brick, bamboo, or timber and in modern times engineers have employed iron, steel, and concrete, among other materials, to give bridges their basic functional utility as crossings. Underfoot and serving essentially to span a deep gorge, a broad valley, as well as languid or rushing streams, even their below deck three-dimensionality is usually inconspicuous and little noticed.

However, there are bridges with a striking 'building' rising above its deck. An architectural genre generically called covered bridges, these have been well-known and appreciated for centuries in Europe and North America unlike in China where they have been little noticed until recently. This essay examines briefly those in North America and Europe while subsequently elaborating examples of extraordinary covered bridges called langqiao 'corridor bridges' in China that exceed those in the West in terms of number, age, complexity, and architectural ambition. Countless Chinese langqiao are undeniably historical edifices epitomising local heritage, deemed worthy of historic preservation, and, are poised to be added to China's Tentative List for inscription as UNESCO World Heritage cultural sites. Moreover, in China today there is a resurgence-what the Chinese call jian qiao re 'bridge building fever'-in which new langqiao are being built throughout the country as iconic cultural markers alongside vertiginous modern marvels of concrete and steel that have been heralded worldwide because of technical breakthroughs.

Determining the earliest appearance of timber bridges in any area of the world or even concluding which is the oldest standing structure seen today are both challenging efforts. The earliest appeared at a time when such structures were not only not noteworthy, but the means of documenting them photographically did not exist. In the 


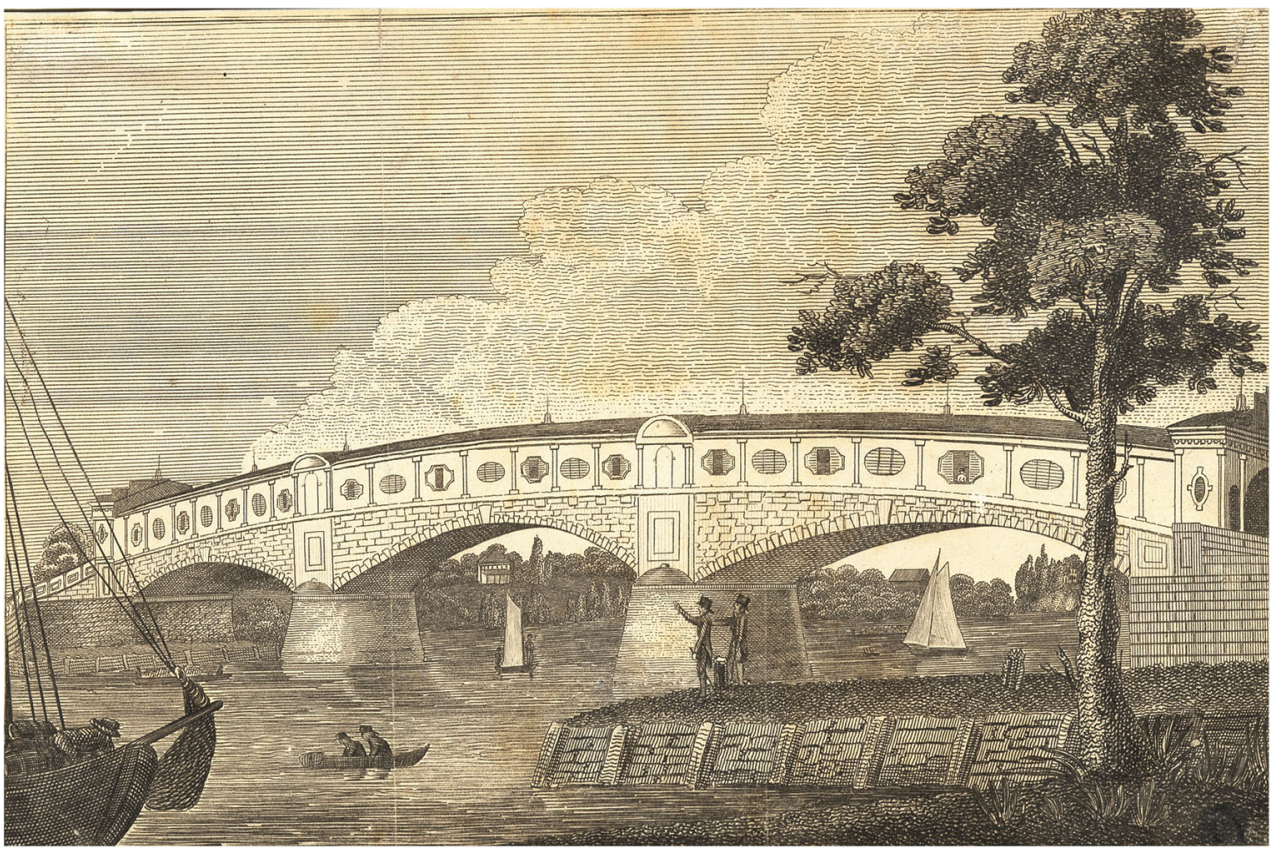

Fig. 4 The Permanent Bridge in Philadelphia, Pennsylvania is considered the earliest documented covered bridge in the United States (Source: American Philosophical Society)

case of very old covered bridges still standing in North America and Europe, moreover, most have undergone rebuilding to greater or lesser extent over the centuries that make dating their original condition difficult, even impossible.

No one has conclusively established when Europe's first covered bridges appeared, but one, Lucerne, Switzerland's Kapellbrücke (Fig. 2) has been dated to c. 1333. Though this bridge is doubtless Europe's best-known covered bridge-photographed by thousands of tourists each summer-it is also atypical in that it is a simple trestle bridge built for pedestrians. Additionally, it is

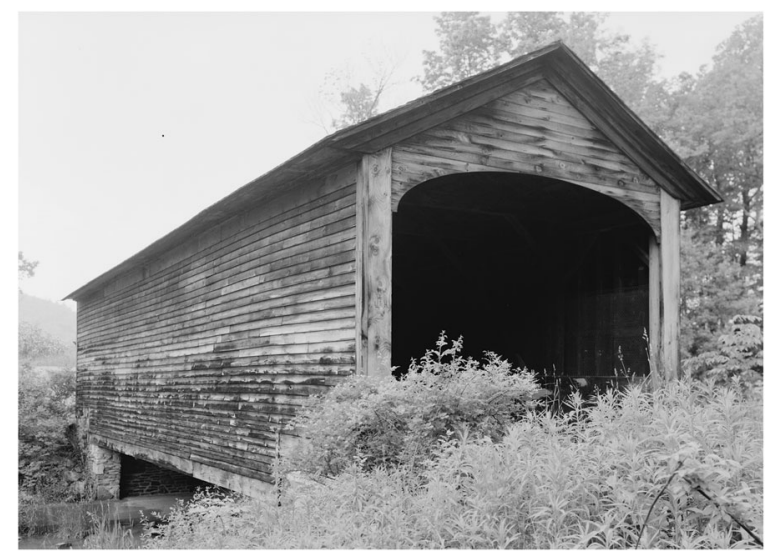

Fig. 5 Hyde Hall Bridge in New York State, said to date to 1825, is the oldest surviving covered bridge in North America (Source: Historic American Engineering Record, US Library of Congress) doubtful that any of its timber structure is very old since, among other calamities over seven centuries, flooding swept away part of it in 1741 and a disastrous fire in 1993 consumed the distinctive gabled roof and the bridge balustrades along both sides.

While Germany, Austria, Italy (South Tyrol), and the Czech Republic also have covered bridges, Switzerland has not only the greatest number but the most significant, since it was the Swiss who perfected the construction of wooden bridges from at least the 16th century. These medieval-styled masterpieces, the earliest spanning the Aare River in central Switzerland, make use of massive beams formed into kingpost and queenpost trusses. Not only are such structures similar to the roof trusses found in churches and great houses but were built by the same craftsmen. Thus, most European bridges built up to about 1850 were simply elaborations of the queenpost, with or without the addition of arches. The Neubrügg (Neubrücke) near Bern was constructed in 1535, has most of its original structural members, and continues to carry motor vehicles (Fig. 3).

The dating of North America's earliest covered bridges is somewhat clearer. Although there is evidence in a drawing that the idea of covering a bridge existed in the United States in the later 18th century, the first documented covered bridge was completed in 1805 in Philadelphia, Pennsylvania. Termed the 'Permanent Bridge', (Fig. 4) the uncovered crossing was completed in 1804 and only covered the following year at the request of the financier who believed that wooden sides and a roof 


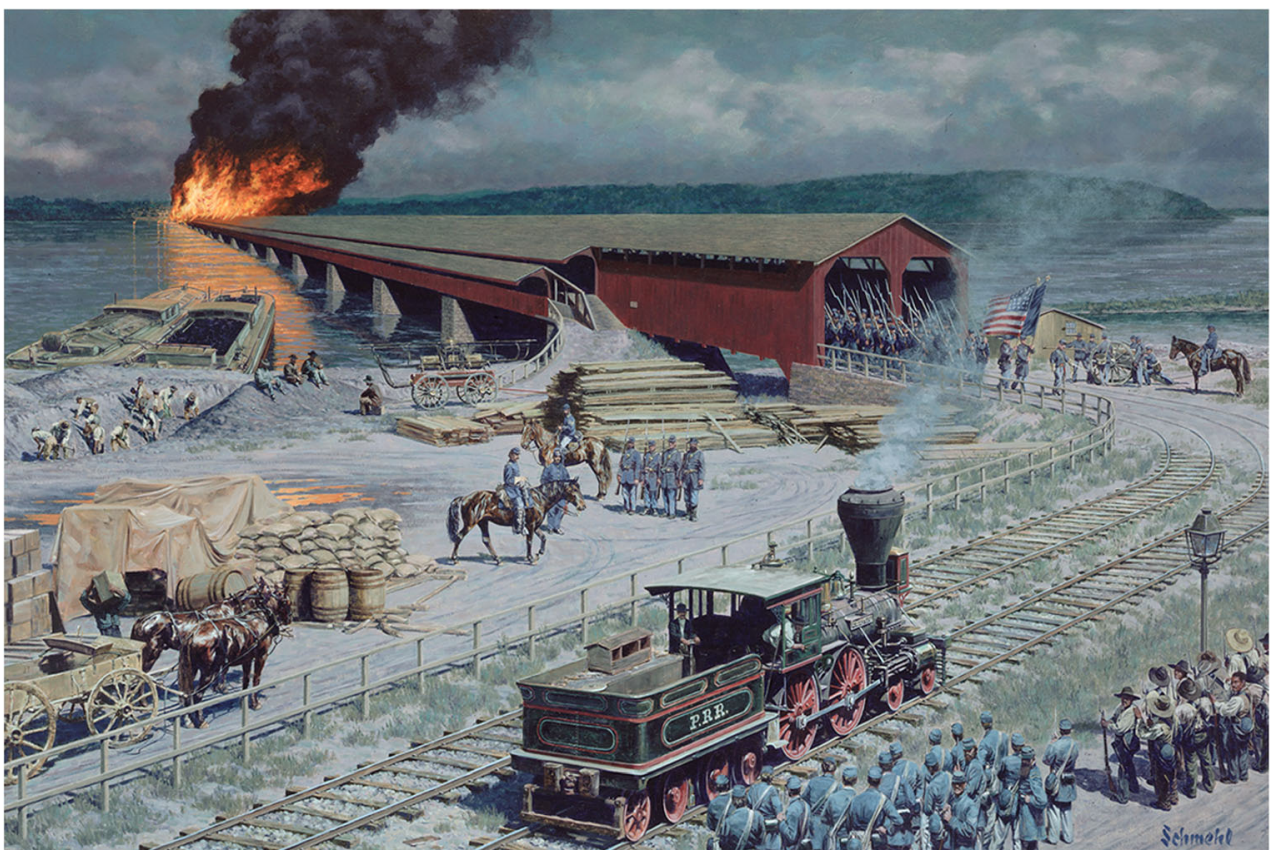

Fig. 6 The $5690 \mathrm{ft}(1730 \mathrm{~m})$ long second Columbia-Wrightsville Covered Bridge in Pennsylvania was burned during the Civil War in 1863 (Source: 'Columbia Bridge Burning' by Bradley Schmehl bradleyschmehl.com)

would prolong its life. Over the next century, covered bridges were constructed in increasing numbers-perhaps as many as 15,000 in total throughout the United States and Canada. Hyde Hall Bridge in New York State, which is the oldest standing covered bridge in North America, dates to 1825 (Fig. 5). With a length of $16 \mathrm{~m}$ (53 ft), it is rather modest; thus, it is not truly representative of the great covered bridges constructed in North America, some of which were nearly two kilometres (more than 1 mile) long like the second ColumbiaWrightsville Covered Bridge in Pennsylvania that was consumed by fire during the Civil War (Fig. 6).

In China, the evidence for langqiao-bridges with a roofed gallery above-is both textual and archaeological. The textual evidence is admittedly fragmentary and conjecturable with the most consistent referring to the famous Ba Bridge, a timber beam bridge outside Chang'an, today's Xi'an, in Shaanxi province, that dates to the Spring and Autumn period ( 771 to $476 \mathrm{BCE}$ ). Much of this is based on the interpretations of Liu Dunzhen, one of China's preeminent architectural historians, that a timber gallery must have been situated above the wooden deck since the length and scale of the bridge was expressed in the number of jian, modular bays, the same term used in measuring buildings on land. Moreover, Liu tells us historical records suggestively state 'one travels several $l i \ldots$ without being able to gaze at the sun' and, that 'one night ... a fire raged from east to west all the way into the morning by which time the bridge was completely consumed by the flames' (Liu
1984, 23). There are no known images of the Ba Bridge (Zhu and Liu 2011).

Archaeological excavations in 2001 at the Jinsha site on the western outskirts of Chengdu, Sichuan province provided evidence of a wooden langqiao that dates to the Han Dynasty (206 BCE-220 CE). While the evidence is imperfect and far from complete-as, it must be admitted, even with authoritative dates for more recent European and American covered bridges-China evidently has the longest tradition of 'covered bridges' in the world with countless numbers lost over time. Rare photographs of late nineteenth and early 20th century langqiao by foreigners, mostly missionaries, explorers, and scientists, reveal levels of unrivaled complexity and beauty that overshadow those existing today. Sadly, most of these bridges did not survive to the last half of the 20th century (Fig. 7). There are several standing bridges in China that vie as the country's oldest as defined by specific criteria, but none currently are earlier than the 15th century.

At this point, it will be useful to examine, if only briefly, the degree to which fieldwork and archival research in China have been entwined with scholarly predilections in a quest to determine 'the oldest' woven arch-beam timber bridge structure in the country. The thread began in 1954 after Tang Huancheng had examined the original 12th century painting Qingming shanghe tu by Zhang Zeduan in Beijing's Palace Museum. Placing this uncovered timber bridge on the cover of his 1957 book, Tang asserted that the underlying 


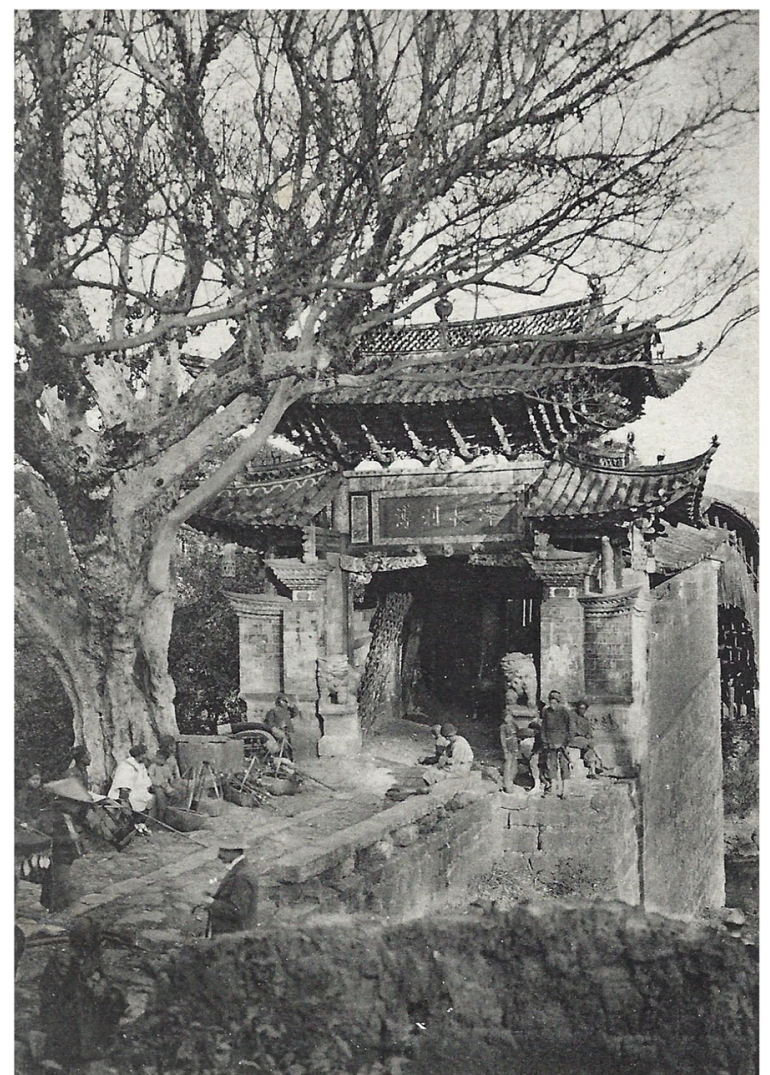

Fig. 7 Photographed and printed on postcards sometime between 1904 and 1910 when the French were constructing a railroad between Haiphong in French Indo-China and Yunnan-fu in China, this elaborate entryway graced a langqiao that no longer exists (Source: Ronald G. Knapp Collection)

structure employed a system of interconnected logs that was 'unique in the world' (Fig. 8).

During the height of the Cultural Revolution in the early 1970s, a small number of Chinese bridge specialists made forays into the generally inaccessible mountains of southern Zhejiang to scout out some extraordinary timber bridges that were being talked about. Later in the decade, these were being called 'rainbow bridges (hongqiao)' and being compared to the soaring bridge in Zhang Zeduan's painting. Yet, it was not until the publication of books by eminent bridge historians Mao Yisheng in 1986 and Tang Huancheng in 1987 that images revealed these 'rainbow bridges' not only had a novel understory but also were covered (Figs. 9 and 10). Although both books included hazy photographs of other langqiao throughout China, the Fujian and Zhejiang 'rainbow bridges' with their intricate under-deck structure called 'timber arch (mugong)' by Mao and 'combined beam-arch (dielianggong)' by Tang, which appeared to mimic the Zhang Zeduan painting, captured the scholarly imagination.

These findings spurred research to search out all langqiao of this type well into the 21st century and have

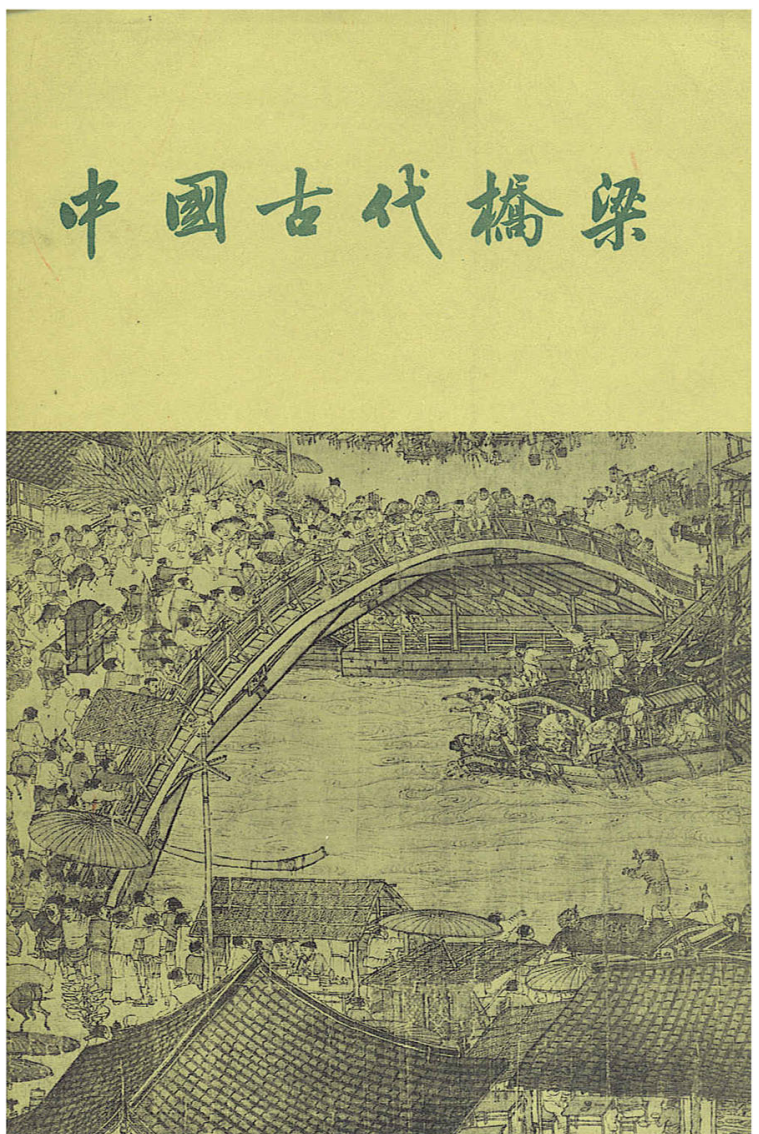

Fig. 8 Highlighting the recently discovered original painting by Zhang Zeduan, Tang Huancheng celebrated the unique character of the interconnected log structure beneaththe deck on the jacket of his 1957 book

resulted in dozens of detailed books about what is now referred to as 'woven arch-beam' timber bridges in Fujian and Zhejiang provinces, a subject discussed below. Among the more than 100 langqiao of this type, the Rulong Bridge, Qingyuan county, in the mountains of southern Zhejiang province is touted as the oldest woven arch-beam timber bridge in China (see Fig. 1). This is principally because of the patrimonic link of its sophisticated under-deck structure that is heralded by many authorities as linked to the structure seen in the 12th century Qingming shanghe tu painting.

Over the past 15 years, efforts have increased to revisit significant clusters of corridor bridges elsewhere in China, but none of this has yet reached the level of attention given to Fujian and Zhejiang woven arch-beam bridges. Moreover, it is unfortunate that only limited attention has been paid to investigating old langqiao with masonry bases and other timber sub-structures, such as those utilizing log beams, both of which offer promising avenues of research. Interesting research continues about Dong (Kam) wind-and-rain bridges, while much 


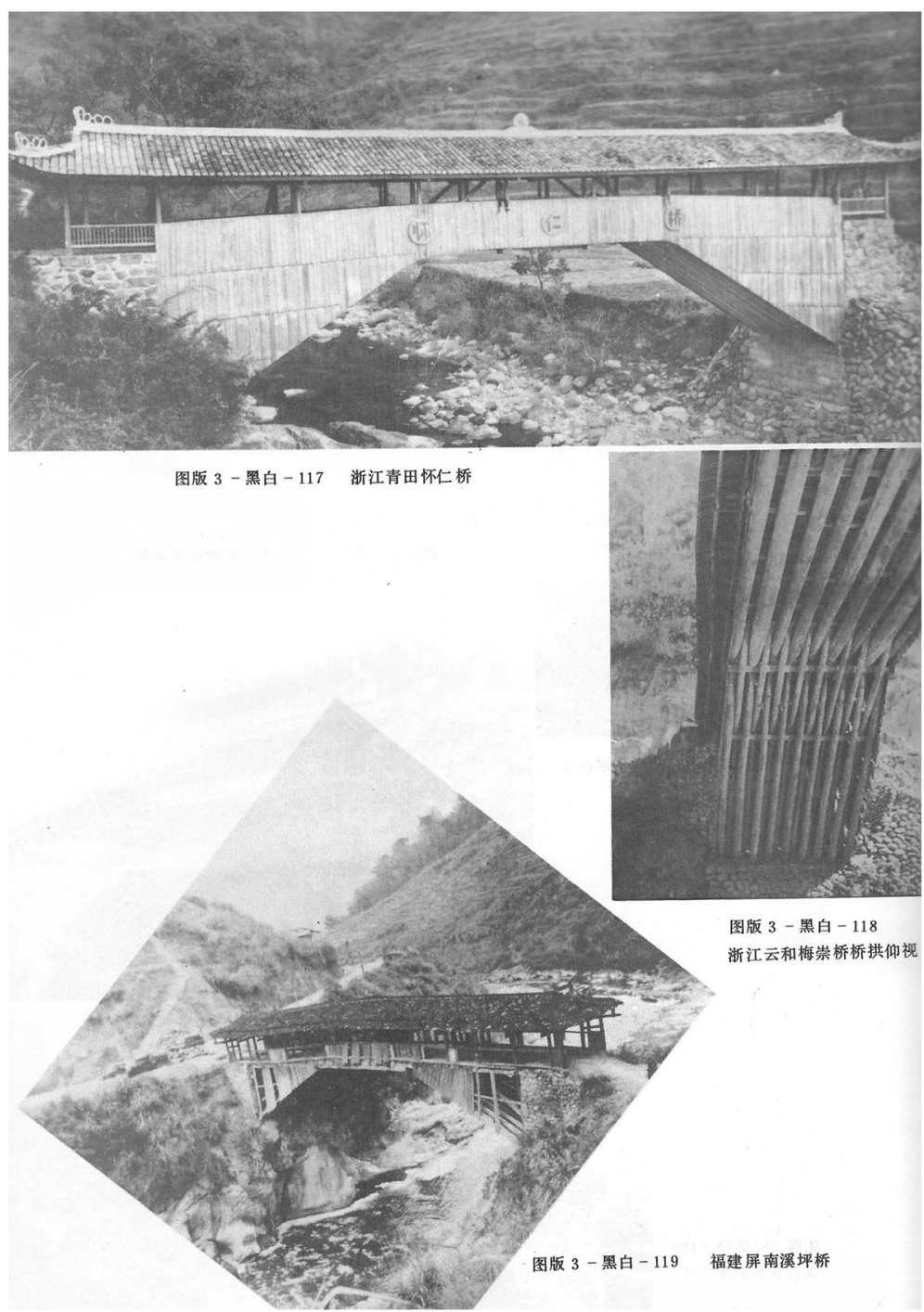

Fig. 9 In 1986, Mao Yisheng was the first Chinese scholar to publish photographs of Fujian and Zhejiang corridor bridges with what he called a 'timber arch' 木拱 understory (Source: Mao 1986)

work still needs to be done concerning those of the Miao, Tujia, and Bai peoples.

\section{Covered bridges and corridor bridges}

To better understand the distinctiveness of China's 'heritage buildings over water', the subtitle of this essay, it is necessary briefly to plumb comparisons with better known covered bridges in the West. These differences can be best understood by presenting information concerning nomenclature and structure, as well as, importantly, function.

Just as buildings on land normally necessitate a foundation to support them, 'buildings over water' not only similarly require abutments and possibly piers to underpin them, this support must be sufficient to overcome gravity since a void must be spanned with any bridge. Thus, it is necessary to look both at the substructure whose function is to prevent the collapse of the bridge as well as the structure above the deck-'the building'-as well. Moreover, as will be detailed below, the striking differences in functionality are crucially important in differentiating Western 'covered bridges' and China's 'corridor bridges'.

The English descriptor 'covered bridge', which is similar to the terms translated from other European languages, emphasizes 'the cover' that comprises the roof and siding that rise above the deck. The use of this phrase, however, prompts the question: 'why is there a need for a cover?' The short and accurate answer from those knowledgeable about the subject in Europe and North America is 'to protect the trusses', which triggers two other questions: 'what is a truss' and 'what purpose does a truss serve'. 
Before wooden trusses were employed, the span of a timber bridge was limited by the quality of the logs employed to cross open space. Indeed, the earliest precursor log bridges were simply tree trunks laid from bank to bank. Well into the modern period, felled logs, while versatile and widely used to form a narrow crossing, were subject to rot, decay, and sag stemming from their natural physical properties. Some pragmatic carpenters, attuned to practicality and experimentation, discovered that it was possible to utilize an assemblage of timbers situated above otherwise weak logs to reinforce them and make possible a greater span than that of the $\log$ alone. Before the use of trusses, it was theoretically possible to span a distance greater than approximately

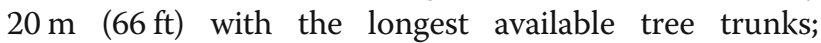

however, from a practical point of view it was rare for a beam bridge to exceed $10 \mathrm{~m}$ (33 ft) in length. Moreover, it was found that the presence of a wooden cover protecting the timber trusses would increase the lifespan of a bridge from perhaps 10 years to many decades, some even claimed a full century. With the addition of a cover-roof and sides-a covered bridge thus became structurally whole as 'a building' just as is the case of a roofed and walled dwelling or other structure.

Whether simple or complex, trusses are fundamentally a configuration of timbers into triangles that act in tension or compression to support the deadload of the bridge deck and cover in addition to the weight of live loads passing across it. Given names such as kingpost and queenpost (Fig. 11), which are the

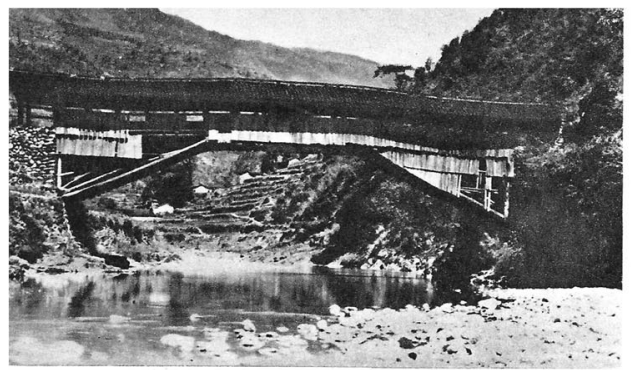

92 浙江云和梅崇桥

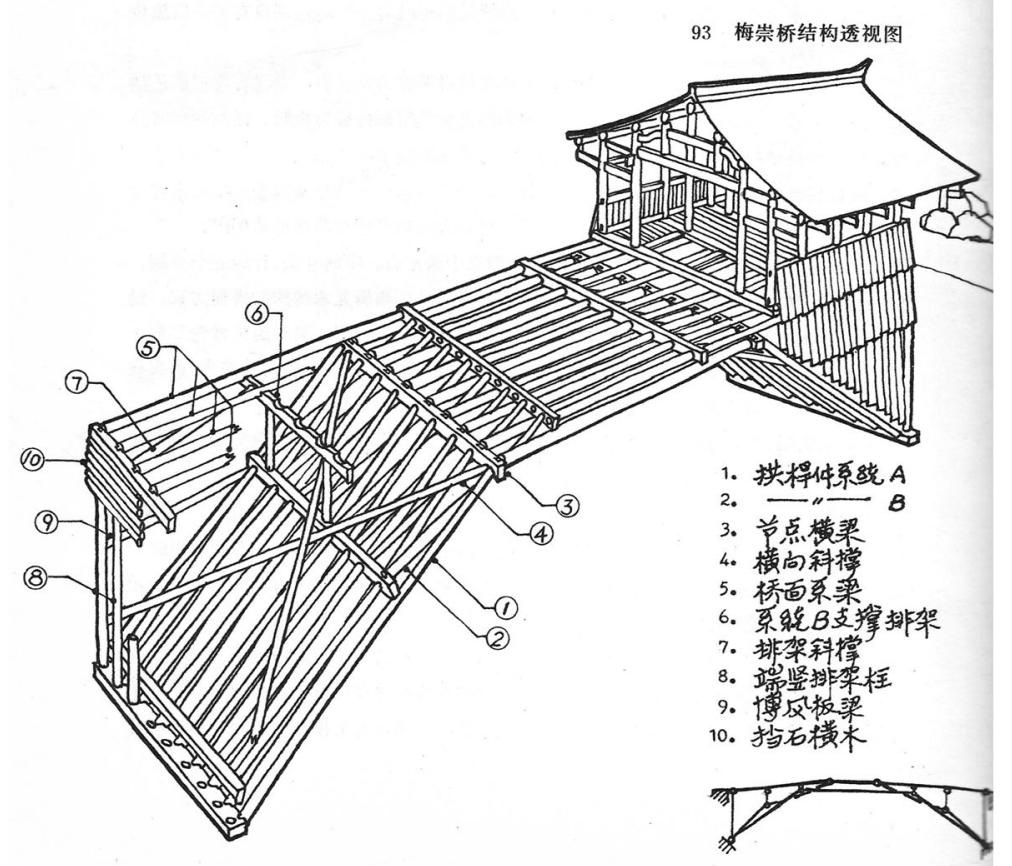

Fig. 10 Using a detailed analysis in his 1987 book of a 'combined beam-arch' 叠梁拱 structure, Tang Huancheng presented drawings, models, and photographs to link the twelfth century uncovered bridge in Zhang Zeduan's painting to this single corridor bridge in Zhejiang (Source: Tang1987) 


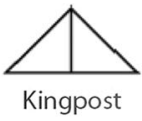

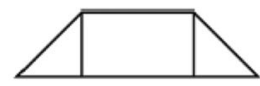

Queenpost

Ancient Truss Types

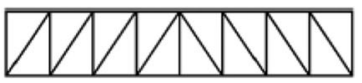

Multiple Kingpost
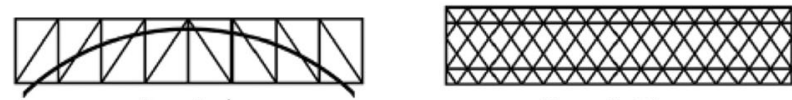

Town Lattice

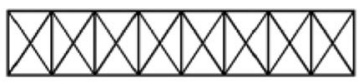

Long

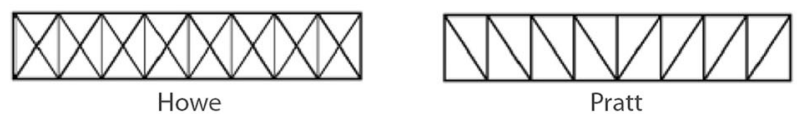

Major Development Truss Types

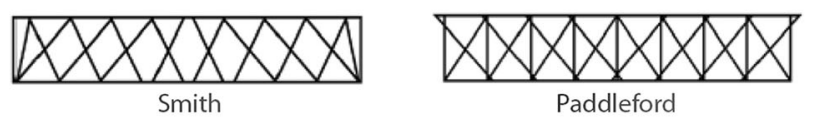

Significant Regional Truss Types

Fig. 11 Major truss types employed in North American covered bridges (Source: Marston and Vitanza 2019, 80)

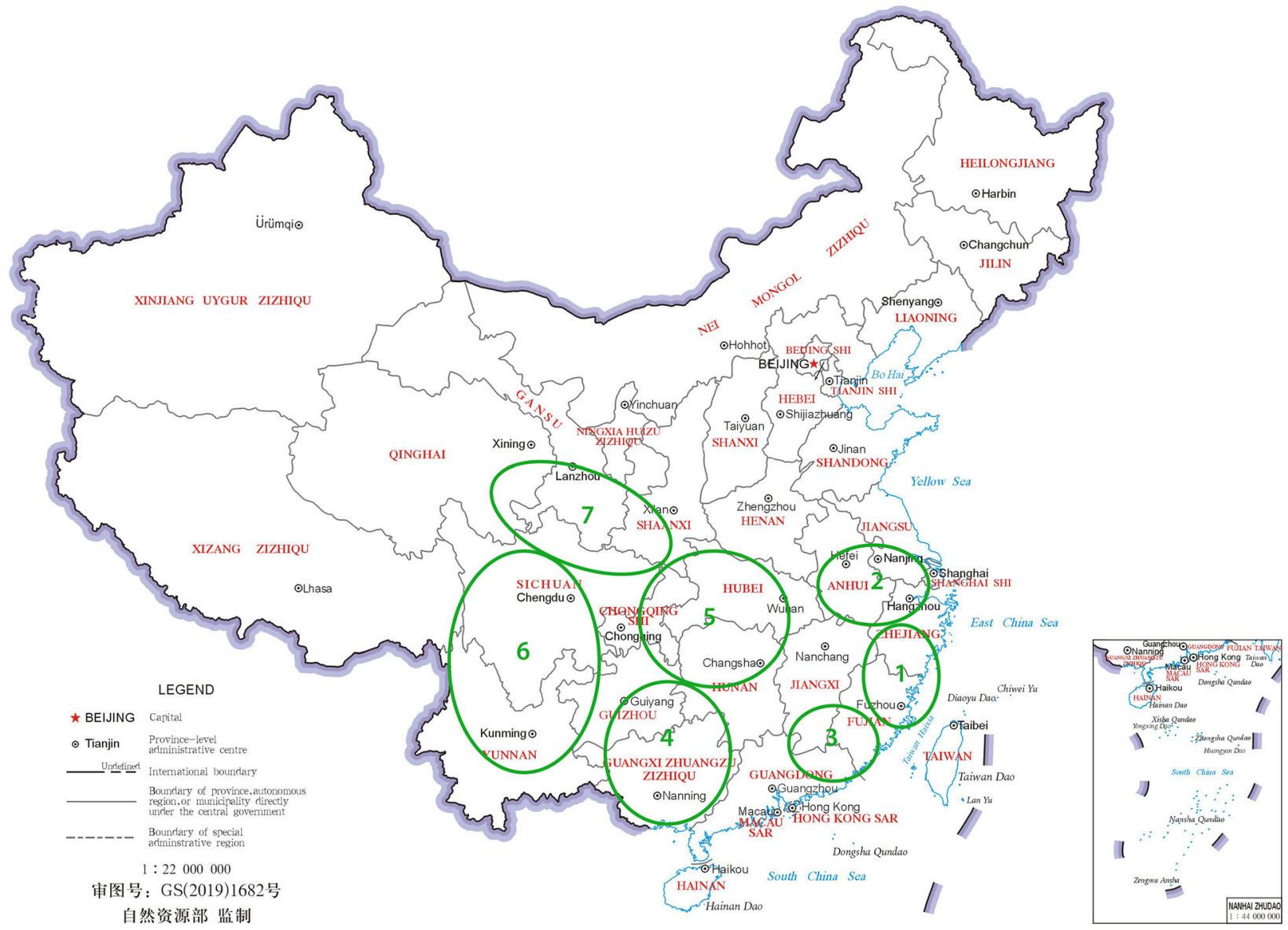

Fig. 12 Generalised distribution of the 7 major concentrated areas of 'corridor bridges' (Source: Ronald G. Knapp) 


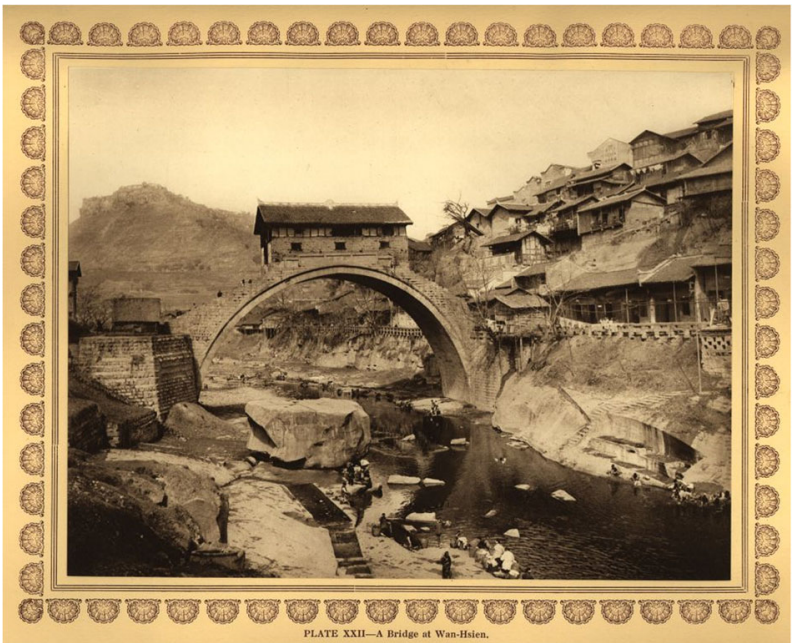

Fig. 13 The steep Wanxian Bridge along a tributary of the Yangzi River in Sichuan province (Source: Mennie 1926)

simplest and oldest trusses, the basic pattern comprises a rigid wooden triangle, which can be multiplied. A carpenter, whether constructing a bridge or a dwelling or a mill, could utilize a truss to span a greater distance than would be possible with a beam alone. Over time in Europe and North America, seemingly endless variations in truss compositions emerged, some of which utilized a wooden arch or metal rods and fastenings to strengthen the triangular assemblage. In the early 19th century in the United States, truss types especially multiplied in number as patents-legal protections for truss designs, that is, the intellectual property of inventive carpenters-became the norm. Among the best known, as illustrated, are those named after Theodore Burr, Ithiel Town, Stephen Harriman Long, William Howe, and

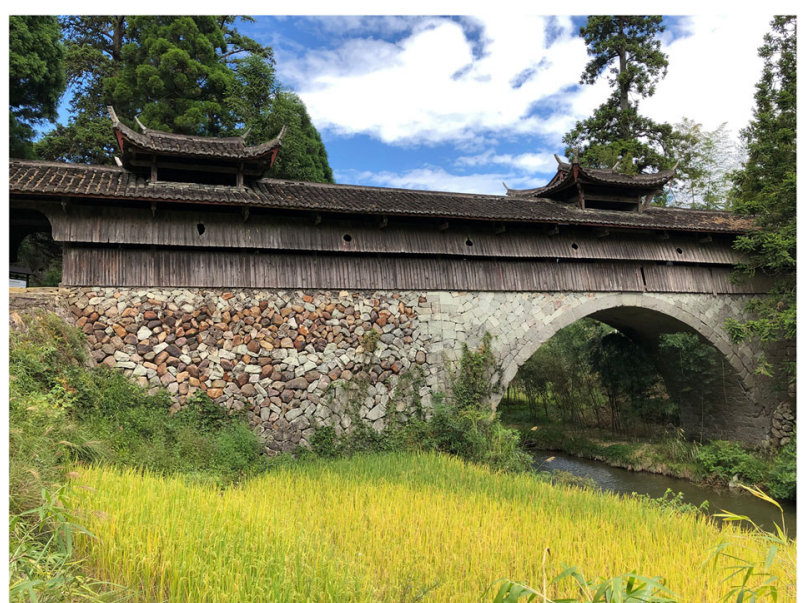

Fig. 14 The timber langqiao rests above an arch base of cut-stone and field stone. Buchan Bridge, Qingyuan county, Zhejiang (Source: Ronald G. Knapp, 2019)
Thomas and Caleb Pratt. ${ }^{3}$ In summary, because of the use of wooden trusses that strengthen it, a covered bridge is a complex specimen of timber craftsmanship that indeed is a building.

\section{Langqiao-masonry and timber bases}

In China, by contrast, trusses as known in the West are not present; thus, the covering-roof and sides-is not needed. In fact, it is important to understand that the Chinese word langqiao does not translate as 'covered bridge' but as 'corridor bridge', a phrase that privileges the linear open space within-the langwu or 'corridor room' measured in terms of jian bay-without any reference to structural elements. In some early works, langqiao indeed were called wuqiao 'room bridge'. Hereafter, the term langqiao will be used when describing such bridges in China even as it is recognized that regionally some are called fengyuqiao 'wind-and-rain bridges', especially in areas populated by ethnic minorities, as well as other local terms such as liangqiao 'cooling bridge' in Tujia minority areas in western Hunan and adjacent provinces, and mисиоqiao 'wooden house bridge' in Fujian. Most of China's timber and masonry 'corridor bridges' langqiao seen today are found in seven regions (Fig. 12):

1. Northern Fujian and southern Zhejiang

2. Northern Zhejiang, southern Anhui, and Jiangnan region

3. Southern Fujian, southern Jiangxi, and northern Guangdong

4. Guangxi, Guizhou, and southern Hunan border area

5. Hubei, Hunan, and eastern Chongqing

6. Yunnan and Sichuan

7. Gansu, Qinghai, and southern Shaanxi

The character of the carpentry that gives shape to the corridor and, of course, supports the roof structure will be discussed briefly in a later section.

Throughout China, there is an extraordinary number of beautiful masonry bridges without an enclosed corridor above that have distinctive designs, substantial proportions, and splendid ornamentation. Virtually all of these have been chronicled well by eminent bridge historians such as Tang Huancheng (1957, 1987, 2018), Mao (1986), Liu, (1979, 1984), Liang Sicheng, Chen Congzhou, Luo Zhewen, and Pan Hongxuan, among others, with extensive notable writings in Chinese as well as accessible illustrated translations in English and other languages. Indeed, it is the uncovered masonry bridges found in China that

${ }^{3}$ For a comprehensive examination of these and other truss types in North America, see Miller and Knapp (2014, 59-97). 


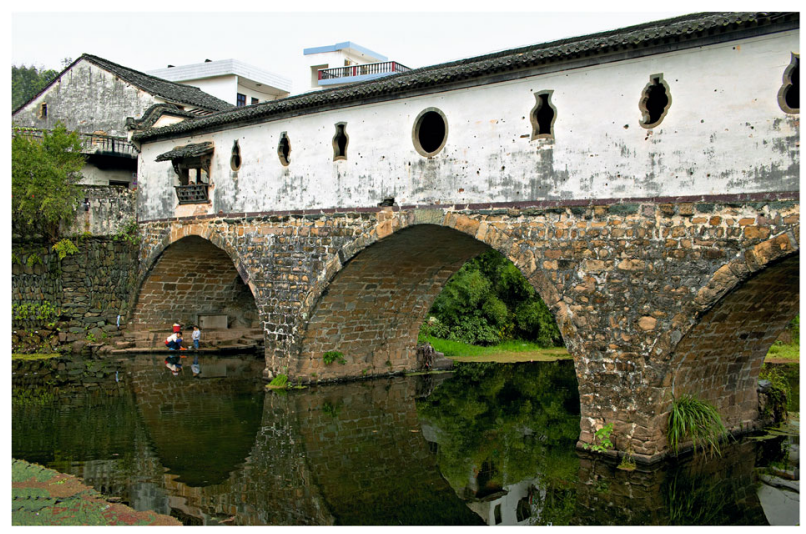

Fig. 15 As with several other corridor bridges in Anhui province, the Bei'an Bridge in Shexian county has an arched under-deck structure of cut stone and upper side walls of fired brick (Source: A. Chester Ong, 2005)

for many throughout the world epitomise the broad classification labelled as 'Chinese bridges'.

Even though none of the famous masonry bridges found throughout China have a corridor above the deck, many langqiao-corridor bridges-have a masonry base. Some of these will be presented here with a greater discussion below of langqiao that have a below-deck timber structure. The fact that none of the langqiao with a masonry base requires a roof and sides to protect them begs the question as to why there is a corridor above the deck. The bases of masonry langqiao are generally constructed of rough-cut stone, river cobblestone, or fired bricks, even occasionally adobe blocks. These materials fully occupy the spandrel, the space between the deck and one or more arches beneath. With shorter bridges, the arch and spandrel are essentially the same length as the bridge but in many cases the base is extended

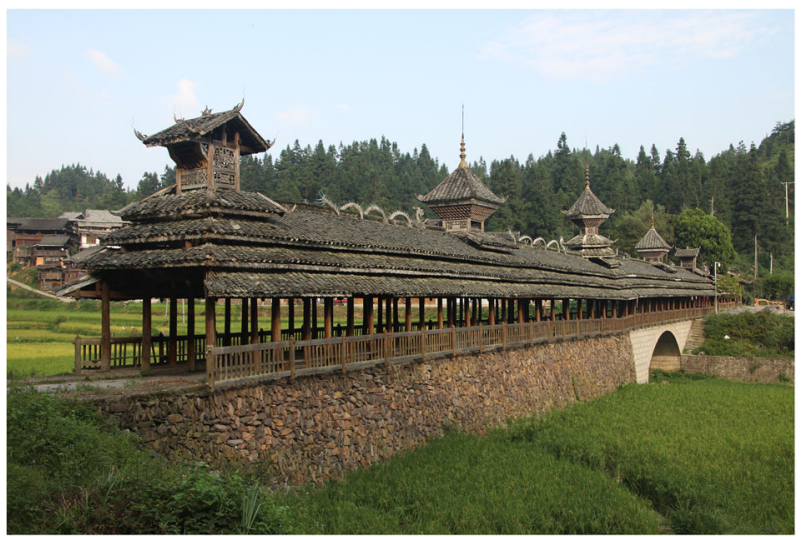

Fig. 16 The wind-and-rain bridges of the Dong minority nationality vary significantly throughout Guangxi, Guizhou, and Hunan. Although the Xiaohuang Bridge only spans a narrow stream, a bulk of its base is a causeway of rubble stone (Source: Terry E. Miller, 2017) significantly. While some, like the high arch of the now gone Wanxian Bridge (Fig. 13), has a thin shell and a steep approach, most, however, consist of one or more arches with a level deck above. Many have additionally on each bank substantial abutments of the same material as that found filling in the spandrel as seen in the Buchan Bridge in Zhejiang province (Fig. 14).

With three prominent arches shaped with cut stone, the $33 \mathrm{~m}$-long Bei'an Bridge in Shexian county, Anhui province, is exceptional in that it has walls above constructed from fired brick (Fig. 15). An interesting feature is that the windows on each side vary. On the east side there are eight large rectangular windows set into the wall while the eight on the west wall each is a different auspicious shape, including a full moon and bottle gourds. Prominent on this wall is a balcony-like feature made of wood that slants outward. Called a meirenkao, these are common features of Huizhou domestic architecture. Inside is a timber framework that supports the roof. By contrast, the base of the Xiaohuang wind-andrain bridge in Guizhou province has a single arch with a lengthy causeway-like base constructed of rubble stone that elevates the long bridge above the paddy fields (Fig. 16). In recent years, the bases of new langqiao are usually of reinforced concrete using the same plan of a standard modern bridge rather than using traditional materials (Fig. 17).

\section{Beam Langqiao}

Beyond masonry bases, there are workaday as well as extraordinary langqiao with timber structures below the deck with some having the structural timbers extending into the interior of the corridor. The simplest timber underpinning employs parallel log beams resting on stone abutments and aligned to support the timber corridor above. As a review of historical photographs and fieldwork reveal, countless numbers of this type are short bridges that are not raised high above a stream. In recent decades as efforts have been made to search for old bridges that are still standing in what were once remote areas of Fujian, more than a handful of historically significant langqiao with timber beams have been documented. The most outstanding of these is now acclaimed as China's oldest langqiao. Dating to 1490, the Zhiqing Bridge in Dikou township, Jian'ou, Fujian province, an area noted for its fast-growing China fir trees, has, about one half of the bridge set on land while the other half straddles a languid stream. Above each of the cut-stone abutments is a rather short set of cantilevers that today then are linked by a set of nine parallel logs; one is missing today (Fig. 18). Whether this acclaim will endure is uncertain as diligent historical 


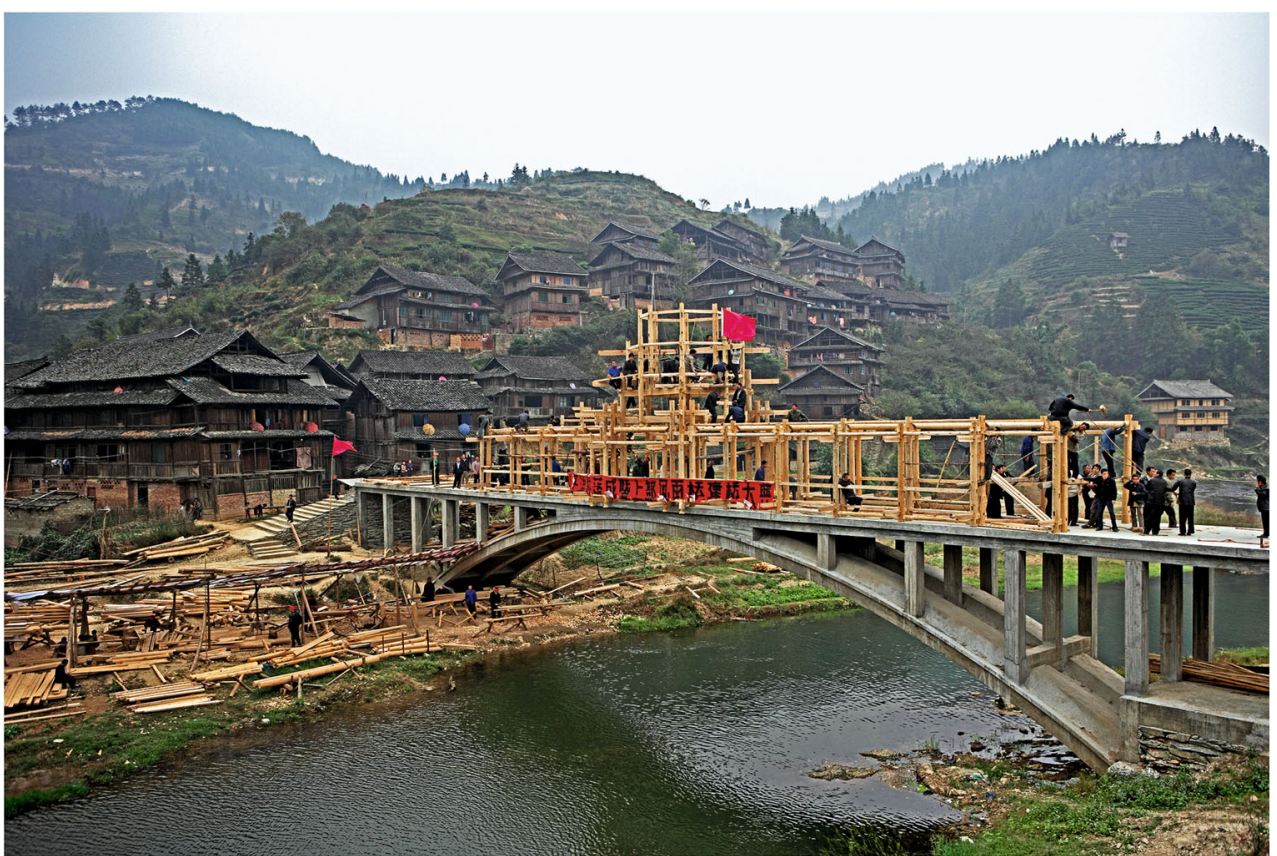

Fig. 17 Raising a traditional timber corridor above a modern concrete base. Sanjiang area, Guangxi Zhuang Autonomous Region (Source: Ronald G. Knapp, 2006)

detective work will continue in search of China's 'oldest' langqiao.

Collectively known as the Zimei 'Sisters' Bridge, which dates to 1873, this paired set of structures in Anzhou district, Mianyang, Sichuan takes advantage of a prominent midstream outcrop to support the ends of substantial timber beams that span the stream (Fig. 19). In this mountainous area, narrow paths drop to the bridge, thus making it possible for villagers to collect medicinal herbs as well as other high value, low bulk plants from remote locations without having to cross a sometimes-unruly stream. Today, the site serves as the anchor for a tourist park. Both interior corridors are quite straightforward

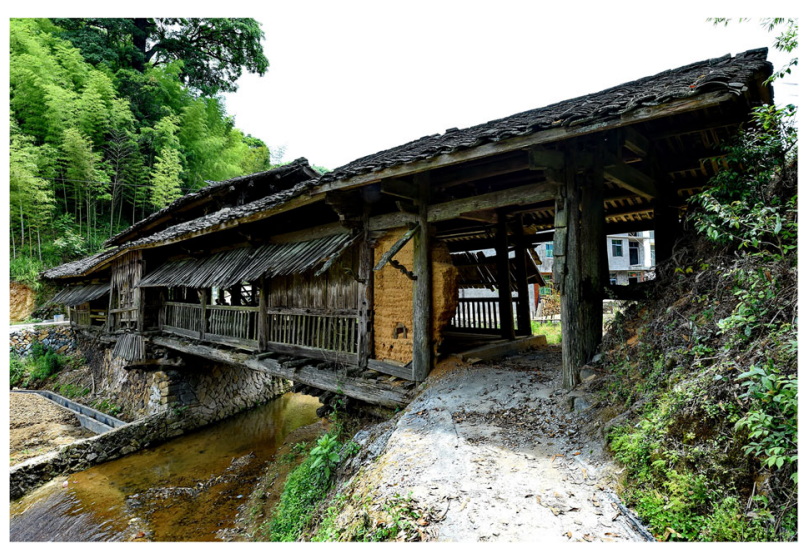

Fig. 18 Said to date to 1490 because of an inscription found on the ridge pole, the Zhiqing Bridge was once supported by ten lengthy log beams (Source: Zhang Guojun, 2017) with mortise-and-tenon joinery used to lock the columns to an uncounted number of beams, roof timbers, and flanking balustrades. Approximately $3 \mathrm{~m}(10 \mathrm{ft})$ wide, the gallery structures are capped with baked roof tiles with rough-cut planks as flooring.

\section{Cantilevered Langqiao}

Stacked cantilevers, both level and angled with staggered members, are found throughout China in order to reduce the clear span with the gap then closed with timber beams. In Fujian and Zhejiang even stone 'log'

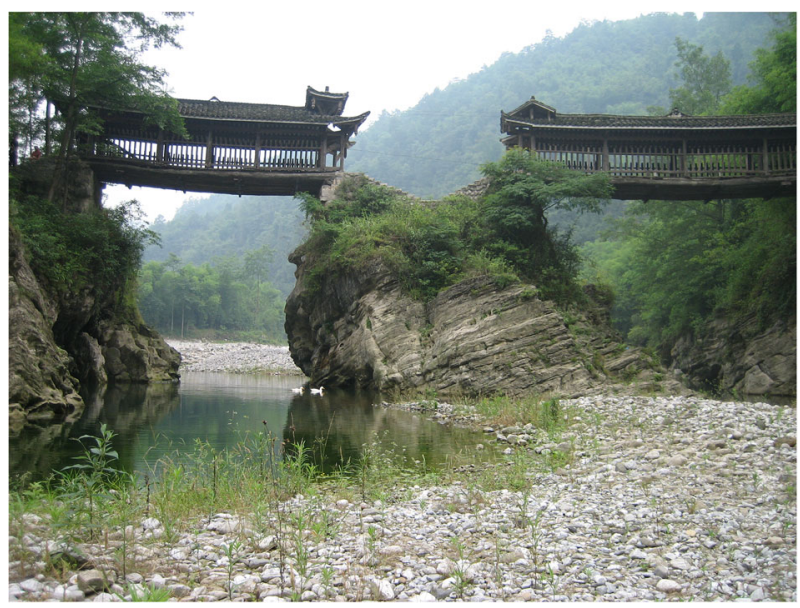

Fig. 19 Zimei Bridge, Anzhou district, Mianyang, Sichuan is a twinned pair of beam bridges with one end of each set on a midstream outcrop (Source: A. Chester Ong, 2006) 


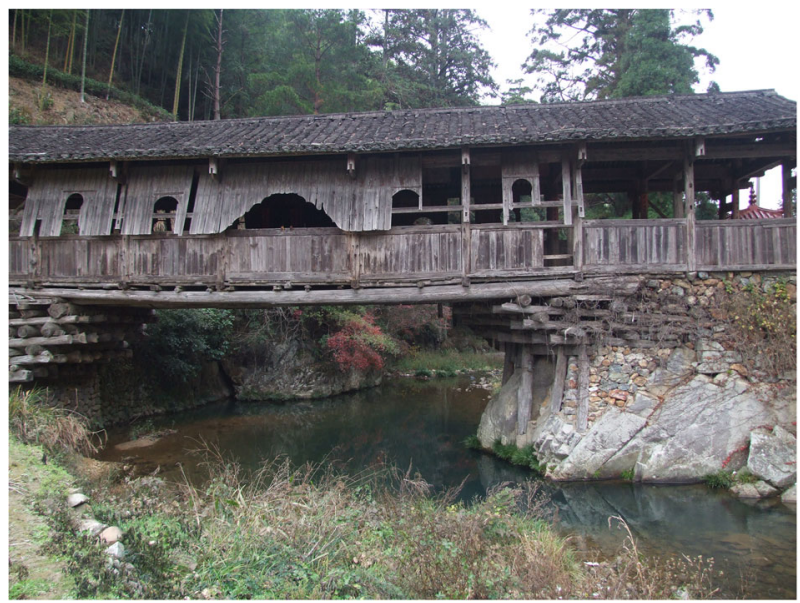

Fig. 20 Stacked cantilevered logs set upon stone abutments are connected by a series of timber beams at the Shuiwei Bridge, Zhenghe county, Fujian (Source: Terry E. Miller, 2011)

cantilevers can be seen. Cantilevers usually are formed from closely spaced members extending in the same direction out from each abutment as well as from each pier for longer bridges. The stacking of some cantilevers involves layers of logs that alternate in direction. In some cases, gaps are left between the logs as seen in the Shuiwei Bridge in Zhenghe county, Zhejiang (Fig. 20).
While there are many modest examples, the most imposing cantilevered langqiao are known locally as 'windand-rain bridges' (fengyuqiao) in Guizhou, Guangxi, and Hunan provinces constructed by the Dong, an ethnic minority group who refer to themselves as Kam (Zwerger 2006). A notable example is the Chengyang (also called Yongii) Wind-and-Rain Bridge spanning the Linxi River in Ma'an Village, one of more than a hundred fengyuqiao in the Sanjiang region of Guangxi province (Fig. 21). Constructed between 1912 and 1924, then rebuilt after being destroyed during a flood in 1983, this fengyuqiao epitomizes the skills of minority carpenters who created unrivaled structures that are distinct from any of the bridges constructed by the dominant Han nationality. Cantilevered layers of fir logs, some 7-8 $\mathrm{m}$ in length, project from the abutments and the top of each stone pier. Above the three mid-stream piers and abutments five elaborate towers with stacked flying eaves endow the bridge with a distinctive architectural rhythm while adding weight that stabilises the cantilevered assemblages. At the centre of the bridge is the tallest tower at $7.8 \mathrm{~m}$, which is topped with a hexagonal structure reminiscent of a drum tower, while the adjacent two towers have pyramidal hipped roofs with four slopes. The end towers have rectangular gambrel roofs, that is, a double slope roof with the upper slope having a lesser pitch than the lower, rising high with five layers. After the building of a nearby modern bridge,

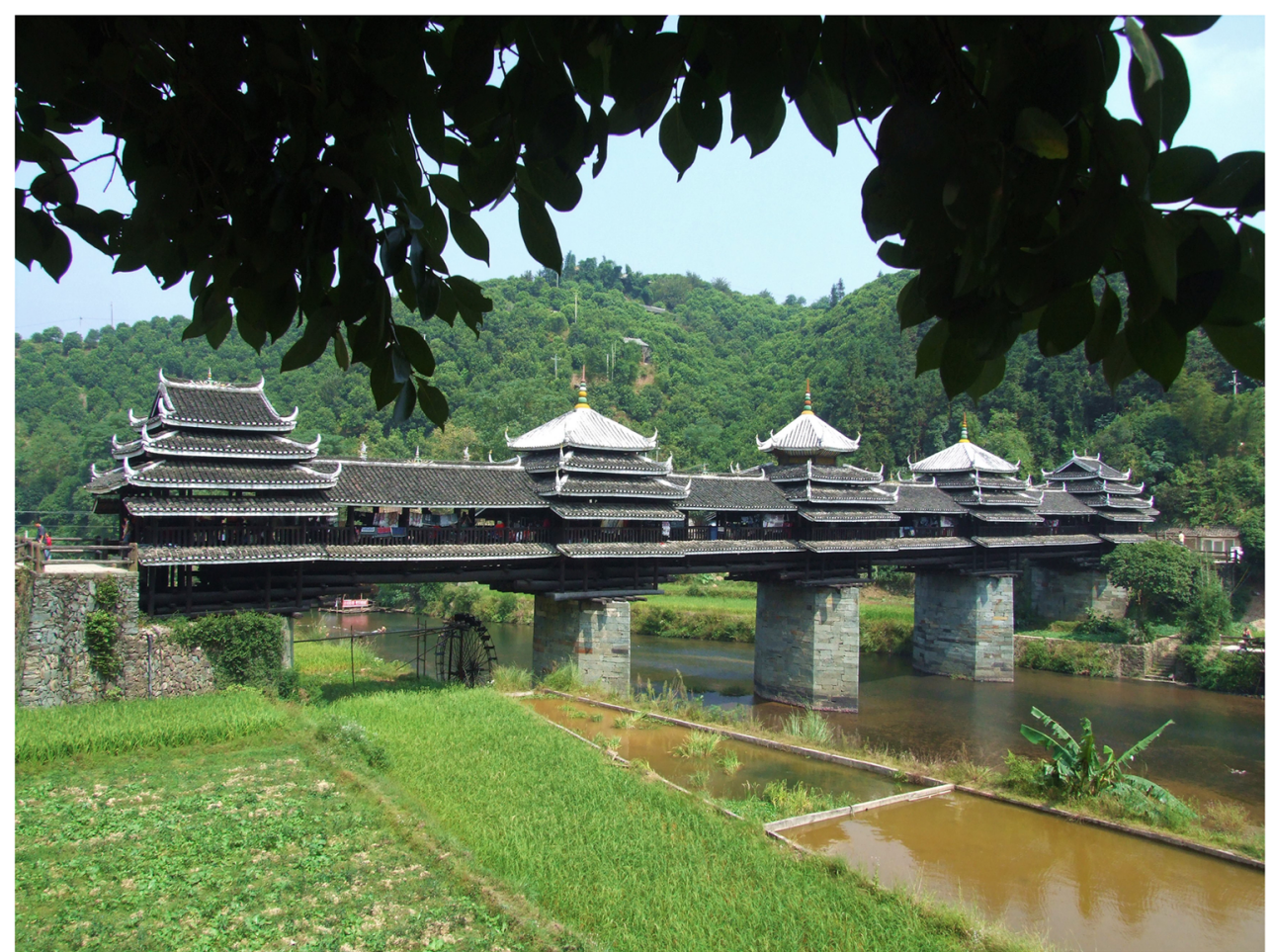

Fig. 21 This wind-and-rain bridge in Ma'an Village, Sanjiang region of Guangxi Zhuang Autonomous Region represents the pinnacle of Dong minority carpentry (Source: Terry E. Miller, 2007) 

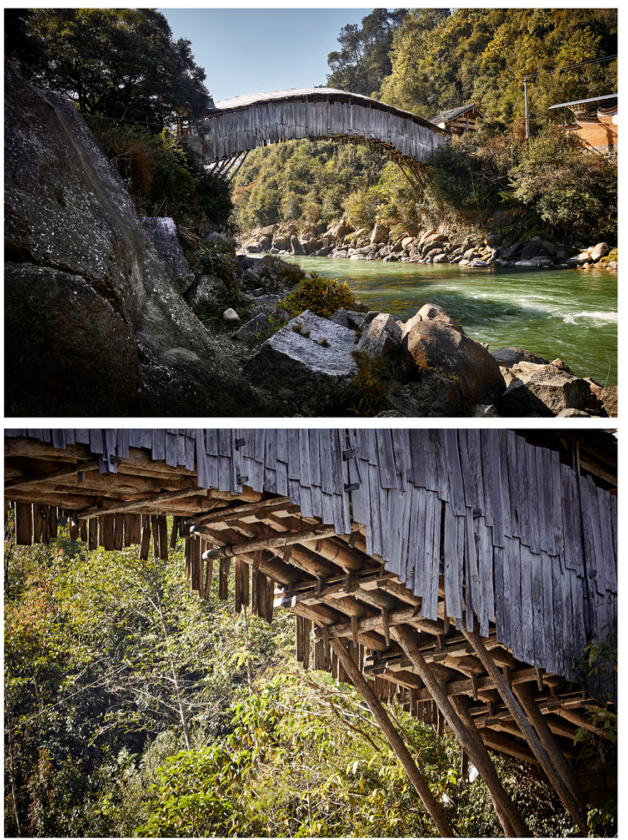

Fig. 22 Rising like a rainbow, the Yezhujing (Chengde) Bridge spans the Longchuan River south of Tengchong, Yunnan (Source: A. Chester Ong, 2016)

this dramatic fengyuqiao no longer carries cart or animal traffic and is open only to pedestrians, the majority of whom are Chinese tourists who encounter villagers sitting inside selling homespun fabrics, embroidered Dong-style clothing, as well as trinkets.

Angled cantilever substructures, which sometimes utilize supplementary angle braces and/or three-piece polygonal arch structures, are most common in Yunnan province. Groundbreaking field work there in 2016 led to the documentation of ten of them. Historical photographs moreover reveal uncovered cantilevered bridges over a wide area in Qinghai, Sichuan, and Tibet, and it is known that there are similar bridges-covered and uncovered-as far away as Nepal and Bhutan. Because the projecting parallel logs are deeply embedded into the abutments and angle upwards, the Yunnan langqiao are 'true' cantilevers even as they vary significantly in terms of angle. The cantilevered logs are socketed into the abutments on each riverbank and stabilised horizontally by crossbeams with a variety of measures employed by carpenters that strengthen the structure. In addition, each bridge has a pair of substantial entryways to the gallery built of tamped earth, adobe brick, and wood that adds mass above to further reinforce the cantilevered assemblage.

There are seven bridges in the Mangbang basin south of Tengchong along the Longchuan River, a tributary that flows meanderingly to the Irrawaddy in Myanmar, which locals say resembles the seven stars that comprise
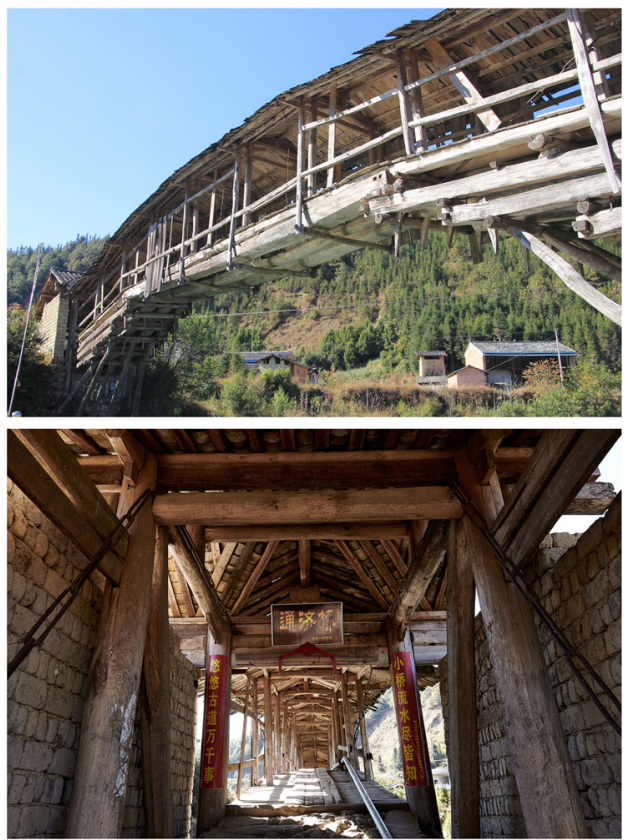

Fig. 23 Though appearing fragile from the outside, the interior of the Tongji (Sunhe) Bridge, Tengchong county, Yunnan is constructed of intricately interlocked timbers (Source: Terry E. Miller and A. Chester Ong, 2016)

the Big Dipper. From north to south, four of these are cantilevered allowing them to soar as 'rainbow bridges', such as the stunning, yet rather rugged, Yezhujing (Chengde) Bridge (Fig. 22a and b). Sweeping high over the river with a clear span of $27 \mathrm{~m}(88 \mathrm{ft})$, the bridge with its gallery has a total length of $30 \mathrm{~m}(98 \mathrm{ft})$. In a region known for torrential rains between June and September that bring rapidly rising rivers, it is not surprising that local carpenters sited bridges high on opposing hillslopes. Records tells us that both a woven rattan bridge and an iron suspension bridge spanned the stream until about 1776, when a timber cantilevered bridge was constructed to replace them because of increasing commercial needs. In 1942, the bridge was deliberately damaged in order to prevent Japanese troops who threatened penetrating Yunnan from Burma. While appearing quite old, the Yezhujing Bridge seen today dates from 1947 to 1948 when it was rebuilt according to the original design. With less use today as a transport link except for local villagers who still cross it with their cattle, the surviving bridge is in a state of deterioration with only minimal repairs.

The relatively narrow interior corridor of the nearby Tongji (Shunhe) Bridge reveals the ingenious carpentry matching practical needs for the passage of humans and animals with the physical attributes of the site (Fig. 23a and $b$ ). Constructed along a trade route during the Ming Dynasty (1368-1744), the bridge was last stabilized in 1946 using sturdy catalpa logs while today it has fallen 


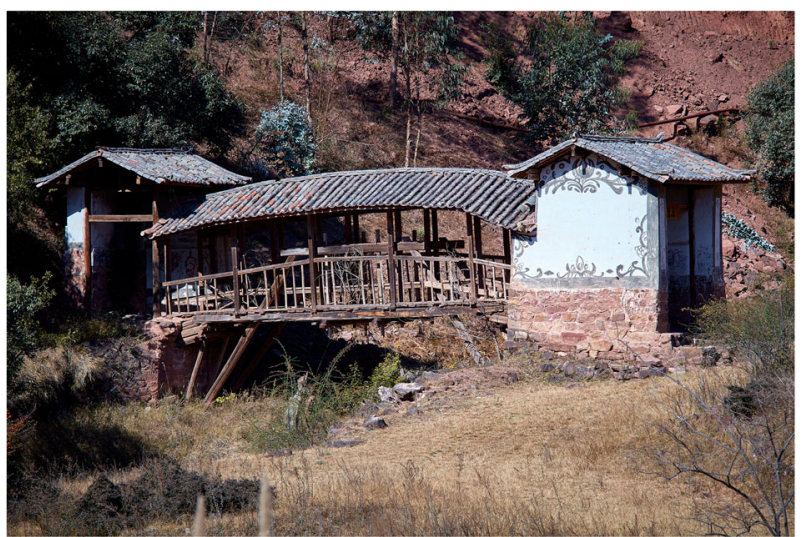

Fig. 24 The modest Wuli Bridge, Dali prefecture, Yunnan has a polygonal arch that supplements short cantilevers below the deck (Source: A. Chester Ong, 2016)

into disrepair. Framed with large timbers, two adobe brick porticos stabilize the steeply tilted cantilever assemblages beneath, which today are propped up with angle braces and reinforced with steel cables. With a $27.5-\mathrm{m}$ (90-ft) span, the bridge seems especially fragile from the outside since none of the siding is in place.

\section{Polygonal arches as reinforcement}

A small number of bridges in Yunnan have in addition to a cantilever structure beneath the addition of threepart polygonal arches that project at an angle from the abutments into the corridor where a horizontal beam joins them (Fig. 24). These reinforce the span's deck with metal rods or wooden verticals joining the arch with the deck base. Whether these constitute a truss or not depends on one's interpretation.

\section{Woven timber arch-beam Langqiao}

The most extraordinary and sophisticated timber langqiao are seen in Fujian and Zhejiang provinces where they epitomize the best of Chinese carpentry. More than one hundred bridges with intricate 'woven arch-beam' timber substructures placed beneath the bridge easily go unnoticed by those passing through the corridor. Widely distributed and diverse in forms, some are single span while others have as many as six spans. Single spans range from a minimum of nine metres to a maximum of more than $30 \mathrm{~m}$. Most of these langqiao, such as the Santiao Bridge in Taishun county, Zhejiang, soar from their abutments above a deep gorge (Fig. 25a and b). This was made possible by inserting logs into stone sockets on the stream bank that were then angled upward in an interdigitating or 'woven' pattern. The vast majority combine at least two sets of polygonal timber arches with the second set having different sectional proportions from the first. Commonly one
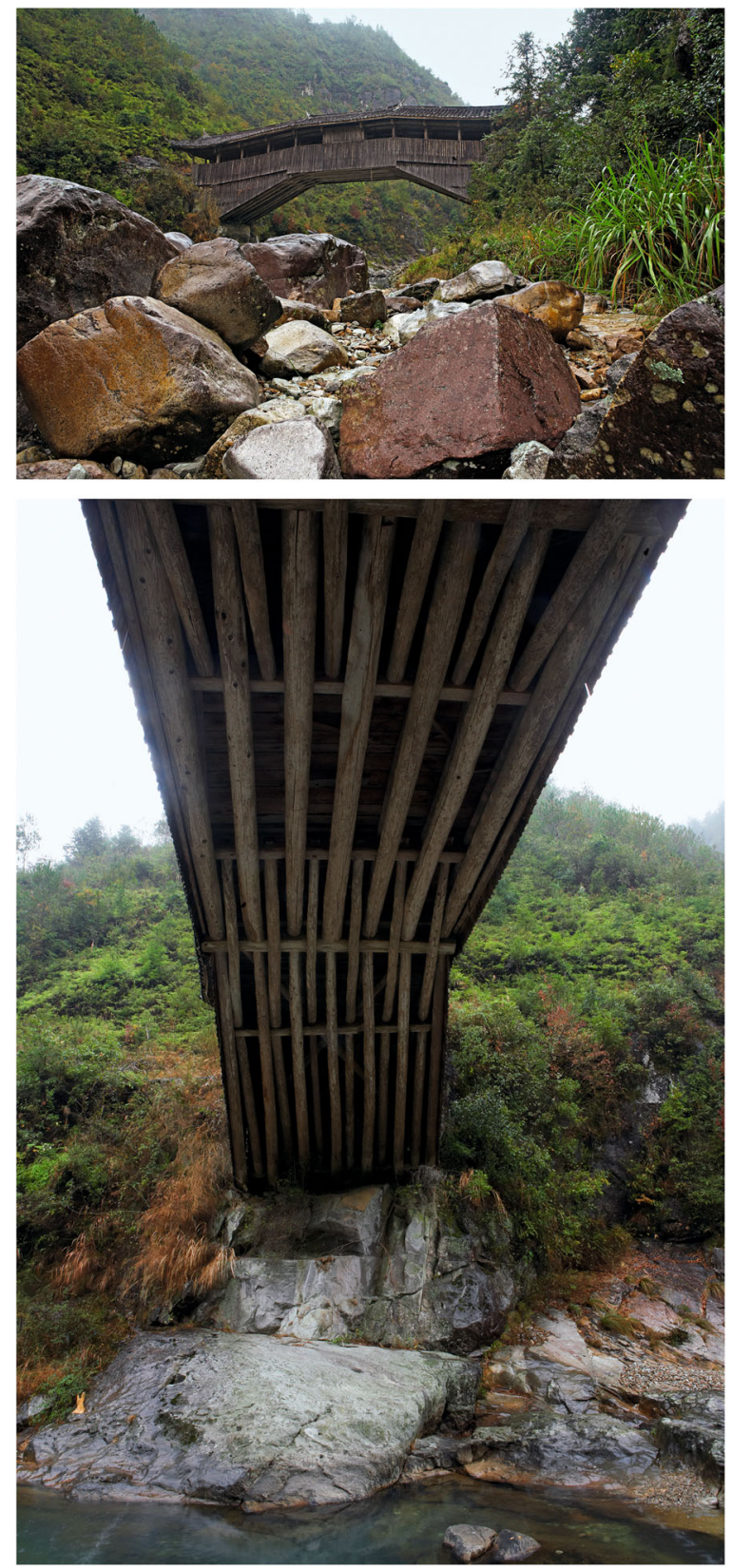

Fig. 25 The Santiao Bridge in a remote area of Taishun county, Zhejiang spans a boulder-strewn stream. Its woven arch-beam structure springs from a streamside rock (Source: Ronald G. Knapp, 2013 and A. Chester Ong, 2006)

set has three sections while the other has five. At each angle-junction the timbers fit into dapped crossbeams, locking the structure in place. Consequently, woven arch-beam bridges depend on gravity, thereby requiring the weight of the corridor for stability since both water and wind could potentially lift the bridge, causing it to fall apart. This kind of modular construction also allows for the easy replacement of worn or deteriorated beams. 


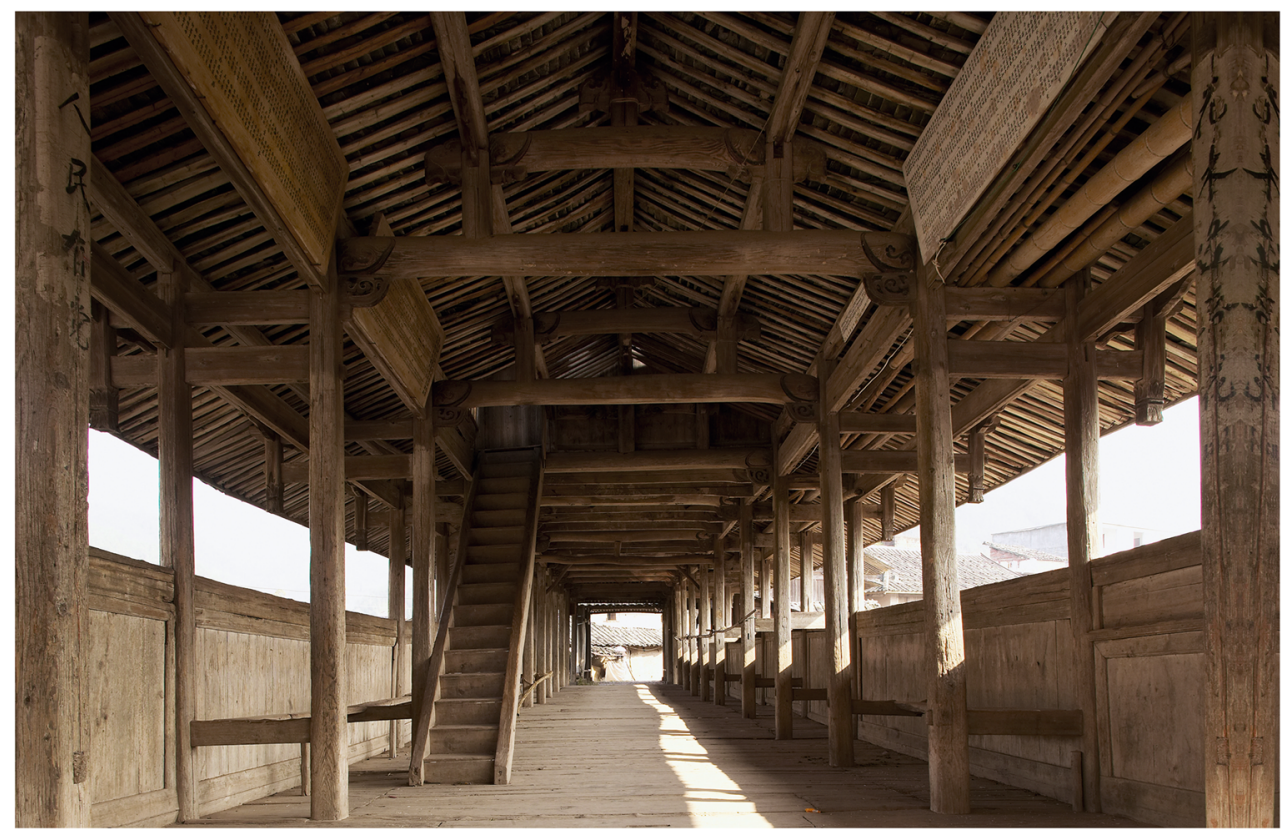

Fig. 26 The rebuilt interior of the Yongqing Bridge, Taishun county, Zhejiang, which dates to 1797, has a classic chuandou timber framed corridor (Source: A Chester Ong, 2006)

\section{Carpentry of the corridor}

While the descriptions above focus on the masonry or timber structures below the deck, it is the corridor constructed of wood that also is a distinctive feature of any langqiao. Before looking at the two basic types of timber frameworks, a brief explanation of the meaning of jian or bay is necessary. Basically, a jian is a volumetric measure of the space that is defined by four columns. A series of adjacent jian defines the rectangle that is the langqiao corridor. Just as with a residence, temple, or palace, the extent of the structure is expressed in terms of how many jian are aligned together. The dimensions of jian vary significantly depending on the size of the building within which they are located.

Chinese architectural tradition privileges wooden framework construction (mujiagou jiegou) as an axiomatic element of all buildings at various scales and, not surprisingly, in the wooden corridors of langqiao. Two basic wooden framework structures dominate that are arranged parallel to the gables and tied together by beams and roof purlins: pillars-andtransverse-tie-beams chuandou and columns/posts-

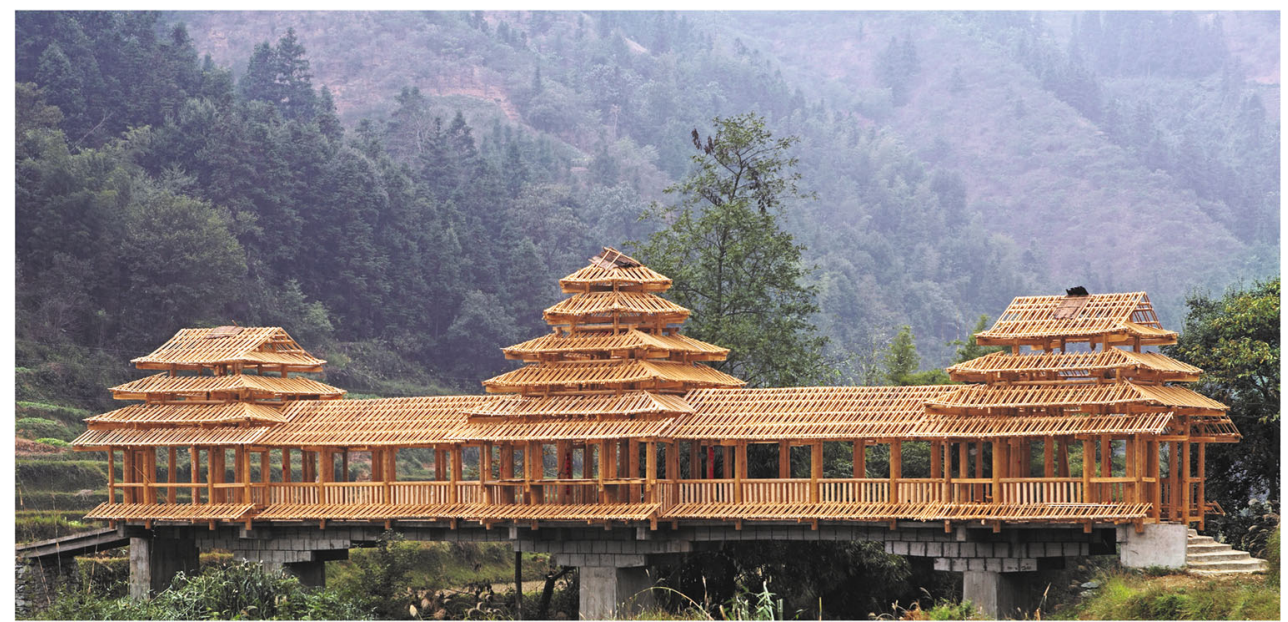

Fig. 27 This view of a newly constructed Dong minority bridge in the Sanjiang area of Guangxi Zhuang Autonomous Region underscores the extent of the timber superstructure of a fengyuqiao (Source: A. Chester Ong, 2006) 
and-beams tailiang (also called liangzhu). ${ }^{4}$ The tailiang system is commonly found in imperial architecture and is widely employed in northern China for residential structures. Chuandou frameworks are most common throughout southern China in both residential construction and langqiao corridors. While each of these systems is relatively uniform in major buildings, including significant corridor bridges, there is much mixing of forms in smaller langqiao where carpenters work flexibly with available timber to meet their objectives. While the central corridor is framed with a pair of pillars, an additional outer set of pillars makes possible the extension of the eaves and provides adjacent space for seating (Figs. 26 and 27; see also $16,17,23 \mathrm{~b}$, and 28 ).

The basic tailiang framework is made up of pairs of pillars that each support a long beam above which two short posts rise to lift a beam on which is set a central kingpost that supports the ridgepole. Purlins-horizontal longitudinal timbers-are set directly upon each beam, indeed often tenoned into the beam. Together these define the slope of the roof. Although tailiang rarely are the principal timber frameworks within a langqiao corridor, they are sometimes mixed with chuandou. Chuandou framing systems differ from the tailiang system in several important ways in giving shape to the bridge corridor: the full-length pillars directly support the roof purlins; utilize smaller diameter timbers that are often misshapen; and horizontal tie beam members are mortised directly into or tenoned through the pillars to form an interlocking matrix that usually extends outside the corridor. Although the timber framework is generally left unpainted to weather with a natural patina, some structures in the minority areas of south-western China are painted.

\section{Functional differences}

What clearly differentiates China's corridor/covered bridges from others in the world is how they are used. Covered bridges in the West were built to accommodate horse or ox-drawn wagons laden with farm products, coal, iron, and brick or rocks as well for wheeled conveyances such as carriages and coaches transporting people, horses and riders, pedestrians, and herds of animals. Unique to North America were covered bridges constructed to carry railroad trains or canal boats floating in aqueducts, troughs of water, over rivers. Langqiao, on the other hand, traditionally served principally to facilitate the transit of porters on foot carrying a shoulder pole (Fig. 28), pulling a handcart, or leading a surefooted pack animal, as remains true today as well (Fig. 29). The narrow, often steep stone paths leading to and from

${ }^{4}$ For a full description of these framing systems, see Knapp (2000, 7788) and Zwerger (2015, 266-275).

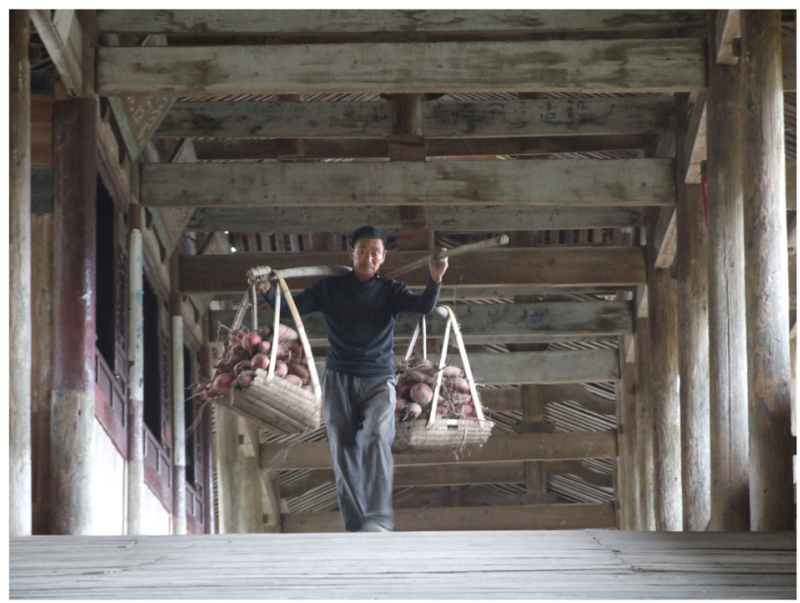

Fig. 28 Beijian Bridge, Taishun county, Zhejiang is heavily visited today by tourists even as it serves as a passage for local farmers who carry sweet potatoes from fields to homes (Source: Ronald G. Knapp 2013)

many langqiao attest to this as do the steps that sometimes must be mounted to enter.

The significance of langqiao in China's economic history is revealed when one maps the location of individual bridges in what appear to be remote mountain areas. It then becomes clear that langqiao and smaller slab bridges were critical nodes in a vast network of stone trails connecting villages and market towns that brought high-value, lowbulk commodities such as medicinal herbs and teas to cosmopolitan centres, even the imperial court. In southwestern China's Yunnan and Sichuan provinces, langqiao served as links in the complex network called the TeaHorse Road (chamadao), which facilitated the movement principally of tea and salt into Tibet where it was exchanged for small horses, medicinal herbs, musk, horn, and other products.

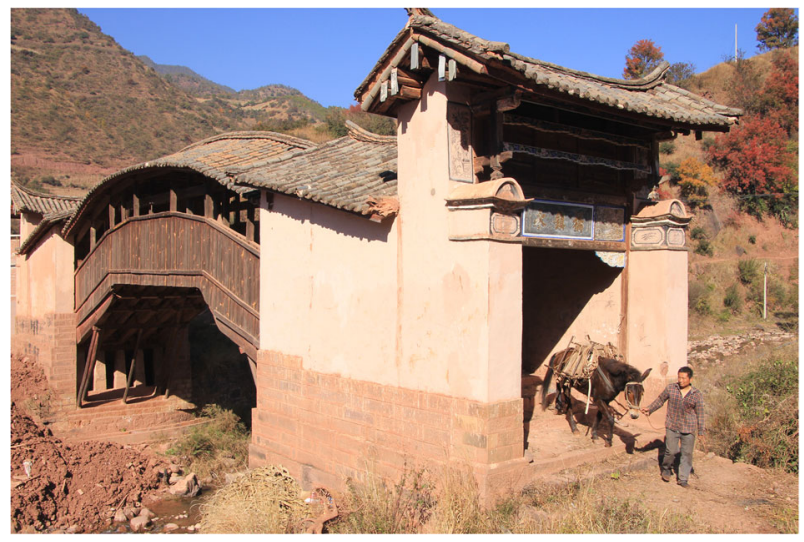

Fig. 29 Said to have been originally built in 1741, the modest, Yongzhen Bridge, Yunlong county, Yunnan, was once a crossing on the Tea-Horse Road, but today serves local villagers only (Source: Terry E. Miller, 2016) 
Like other rural buildings langqiao are bound up with local folk culture including the selection of the site according to fengshui, determination of auspicious dates for specific actions, performance of ritual during construction, presence of auspicious and protective amulets, and, importantly, the utilization of the space. Most critical was the orientation of the abutments, which was determined by a fengshui master with a compass in hand who surveyed possible sites. Indeed, Chinese bridges are sometimes encountered in what seem to be inexplicable locations but in fact were placed there for the purpose of harnessing positive energy as determined by fengshui. Accessing old records confirm multiple langqiao in meaningful compositions to contain good fortune $(f u)$ and to block losing a village's energy. Ritual accompanies the selection of timber, choice of dates for important building actions, especially the selection of and placement of the ridgepole (Fig. 30), called dongliang 栋梁, that mirrors practices in constructing dwellings.

Beyond being a passage from one bank to another, langqiao traditionally served significant social purposes as a resting or socializing place during the day for nearby villagers or townsfolk and overnight shelter for those traveling along remote, often winding, paths. The presence of benches within is clear evidence of these uses. Langqiao near villages provide sheltered space for morning and evening markets (Fig. 31). Today it is common to see the interior of a langqiao functioning as a community centre during evenings and weekends, with tables for games and shops selling snacks. Historically there was an association of bridges with temples and shrines. Within langqiao an altar or shrine (Fig. 32) with local or national deities was located midway along the downstream wall. In some notable cases, a separate temple is adjacent to the outside or even on an expansive second level. Although a few European bridges have within small wall shrines to a Christian saint or the

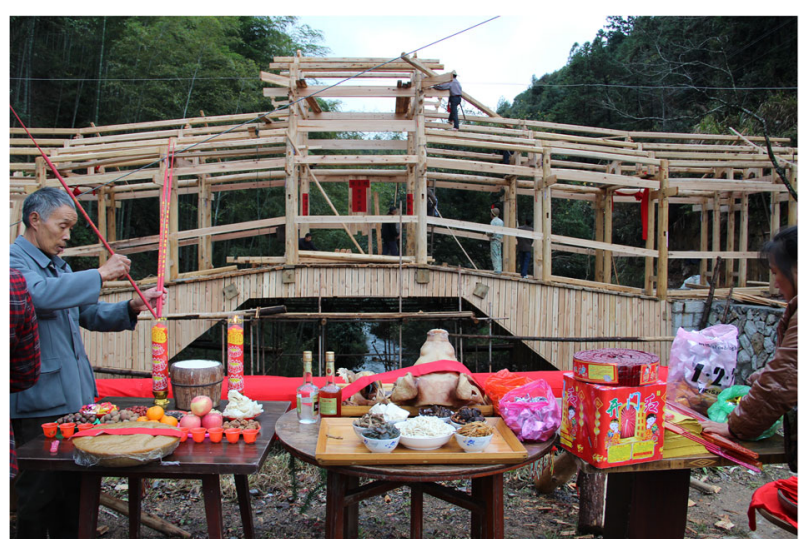

Fig. 30 In preparation for raising the ridge pole, seen behind the table laden with offerings, at the Guanyin Bridge, Shengshuitang village, Qingyuan county, Zhejiang (Source: Liu Yan, 2012)

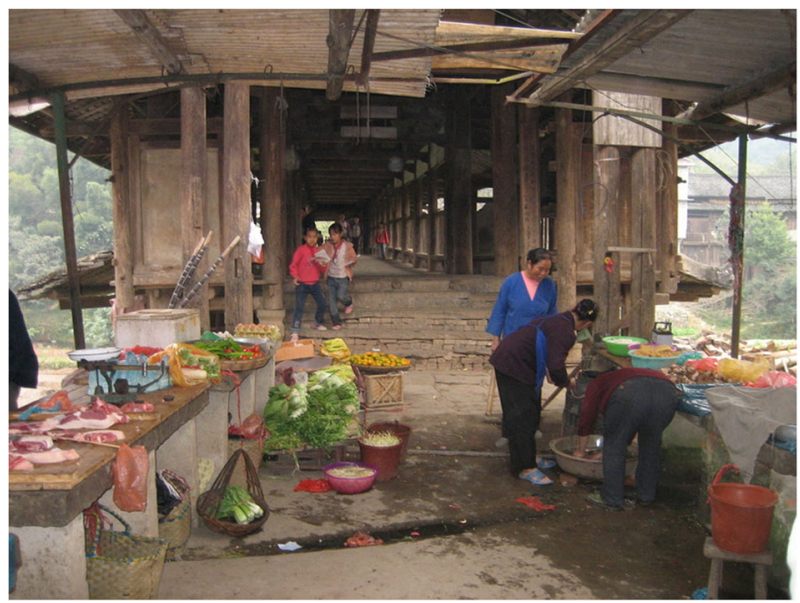

Fig. 31 Morning markets are a common feature at many village corridor bridges, here at the Bajiang Bridge Sanjiang area, Guangxi Zhuang Autonomous Region (Source: Ronald G. Knapp, 2006)

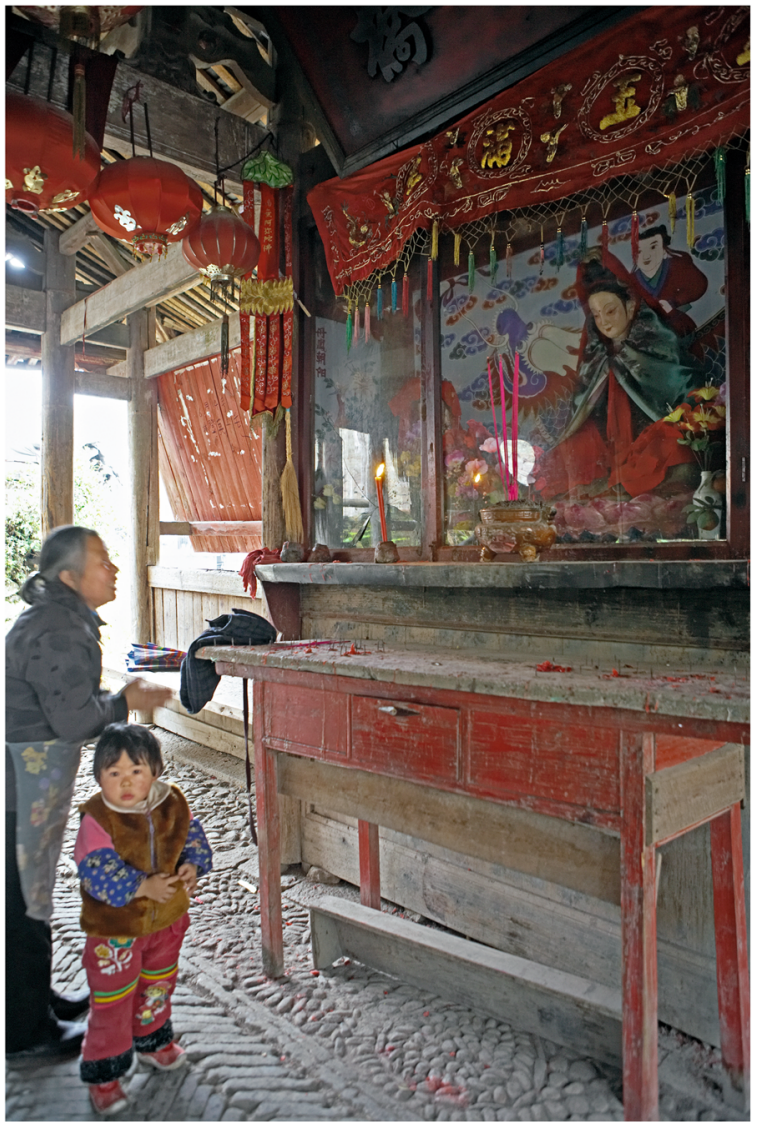

Fig. 32 Situated on the downstream side of most langqiao are shrines to local deities. Baiyun Bridge, Qingyuan county, Zhejiang (Source: Ronald G. Knapp, 2006) 
Virgin Mary, these appear to be memorials rather than sites for actual worship. Whereas Chinese do in fact perform ritual in front of bridge altars, Europeans may do little more than make the sign of the cross. American bridges have no similar shrines even when located near churches.

\section{Conclusions}

Economic development, especially the expansion of modern roads, has made most of the inherited langqiao in China less relevant. While many are no longer necessary to join what is separated or facilitate long-distance trade, many near villages and in towns represent a living tradition as they continue to serve as places for transit, spaces for daily social interaction, and sites for worship. Nonetheless, many indeed stand isolated as structural objects, abandoned and derelict because of their remote locations and no longer functioning as links along mountain paths. Even so, hundreds have been restored or rebuilt and become nostalgic icons for Chinese tourists to enjoy at scenic sites, preserved as a memory of the past rather than for their practical utility. Unexpected a decade ago, increasing numbers of new timber langqiao are being constructed in response to the successful UNESCO intangible heritage listing in 2009. This inscription committed counties in Fujian and Zhejiang to train a corps of timber craftsmen under the tutelage of aging masters, the carriers of traditional craftsmanship. Even beyond Fujian and Zhejiang, such as in Guangxi, Guizhou, and Hunan where two decades ago timber craftsmanship was in decline, new corridor bridges are being constructed (Zwerger 2006). While some of these are admittedly parodies of traditional langqiao, many more are authentic in terms of siting, ritual, and craftsmanship. In some counties, where langqiao have become major factors for tourism, numerous towns and villages are constructing bridges merely as status symbols, rural China's new icon of cultural significance.

Over the past two decades, ephemeral historical records, including building contracts, maps, and poetry have been collected that help complete the documentary record of old bridges that were once neglected. After modest beginnings in 2002, a digital database within the website www.langqiao.net, which focused initially only on Fujian and Zhejiang, has today become quite robust in presenting information about corridor bridges throughout the country. Generally unknown outside China until now, the more than 3000 langqiao far outnumber the celebrated covered bridges in North America and Europe, deserving acknowledgment as one of the three great covered wooden bridge traditions in the world.

Acknowledgements Not applicable.
Authors' contributions

The author(s) read and approved the final manuscript.

Funding

Not applicable.

Availability of data and materials

Not applicable.

Competing interests

Not applicable.

\section{Author details}

${ }^{1}$ SUNY Distinguished Professor Emeritus, State University of New York, PO Box 365 New Paltz, New York 12561, USA. ${ }^{2}$ Professor Emeritus, Kent State University, 2005 Willow Ridge Circle, Kent, OH 44240, USA. ${ }^{3}$ Professor, School of Design Shanghai Jiao Tong University, 800 Dongchuan Road, Minhang District, Shanghai, China.

Received: 18 January 2020 Accepted: 3 April 2020

Published online: 22 July 2020

\section{References}

Knapp, Ronald G. 2008a. Chinese bridges: Living architecture from China's past. Rutland: Tuttle Publishing

Knapp, Ronald G. 2008b. Rainbows and Centipedes: $20^{\text {th }}$ century discoveries of China's 'lost bridges'. Orientations 39 (4):30-39.

Knapp, Ronald G., Terry E. Miller, and Liu Jie. 2019. Zhongguo langqiao: shuishang de jianzhu [China's covered bridges: Architecture over water]. Shanghai: Shanghai Jiao Tong University Press.

Liu, Dunzhen. 1979. "Zhongguo zhi langqiao." [China's Covered Bridges.] In. Kejishishi wenji [History of Science: Article Collection] Vol. 2, 9-13. Shanghai: Shanghai Scientific \& Technical Publishers.

Liu, Dunzhen. 1984. "Shizhouzhu qiao shuyao." [Summary of Stone Axis Bridge.] In Liu Dunzhen wenji [Anthology of Liu Dunzhen], 1-34. Beijing: China Architecture and Building Press.

Liu, Jie. 2009. Jiangnan mugou [Jiangnan Timber Structures]. Shanghai: Shanghai Jiao Tong University Press.

Liu, Jie. 2017. Zhongguo mugong langaiao jianzhu yishu [The Architectural Artistry of China's Timber Arch Covered Bridges]. Shanghai: Shanghai People's Fine Arts Publishing House.

Liu, Jie, and CHTS (China Highway \& Transportation Society), eds. 2019. Zhongguo langqiao [Covered bridges of China]. Beijing: China Communication Press Co., Ltd.

Liu, Jie, and Weiping Shen. 2005. Taishun langqiao [Lounge Bridges in Taishun]. Shanghai: Shanghai People's Fine Arts Publishing House.

Mao, Yisheng. 1986. Zhongguo guqiao jishu shi [Technological History of China's Ancient Bridges]. Beijing: Beijing Publishing House.

Marston, Christopher H., and Thomas A. Vitanza. 2019. Guidelines for Rehabilitating Historic Covered Bridges. https://www.nps.gov/hdp/CoveredBridgeGuidelines2 019.pdf

Mennie, Donald. 1926. The Grandeur of the Gorges. Shanghai: Kelly \& Walsh, Limited.

Miller, Terry E., and Ronald G. Knapp. 2014. America's Covered Bridges: Practical Crossings - Nostalgic Icons. Rutland: Tuttle Publishing.

Tang, Huancheng. (1957) 1987. Zhongguo gudai qiadiang [China's Ancient Bridges]. Beijing: Culture Relic Press.

Tang, Huancheng. 2018. Zhongguo giaoliang jishu shi. Di 1 juan, Gudai pian [Technology History of Chinese Brdiegs, vol 1: Ancient]. Beijing: Beijing Jiaotong University Press.

Zhu, Yongchun, and Jie Liu. 2011. "Handai gedao yu langqiao kaoshu." [Examination of the Han Dynasty Court Roads and Covered Bridges.] Architectural Journal, no. S2: 90-94.

Zwerger, Klaus. 2006. Vanishing Tradition: Architecture and Carpentry of the Dong Minority of China. Hong Kong: Orchid.

Zwerger, Klaus. 2015. Wood and Wood Joints: Building Traditions of Europe, Japan and China. 3rd ed. Basel: Birkhäuser.

\section{Publisher's Note}

Springer Nature remains neutral with regard to jurisdictional claims in published maps and institutional affiliations. 